\title{
Podocyte Injury-Driven Lipid Peroxidation Accelerates the Infiltration of Glomerular Foam Cells in Focal Segmental Glomerulosclerosis
}

\author{
Satoshi Hara, ${ }^{\dagger \dagger}$ Namiko Kobayashi, ${ }^{*}$ Kazuo Sakamoto, ${ }^{*}$ Toshiharu Ueno, ${ }^{*}$ Shun Manabe, ${ }^{*}$ Yasutoshi Takashima, ${ }^{*}$ \\ Juri Hamada, ${ }^{\ddagger}$ Ira Pastan, ${ }^{\S}$ Akiyoshi Fukamizu, Taiji Matsusaka, ${ }^{\ddagger}$ and Michio Nagata*
}

From the Department of Kidney and Vascular Pathology, * Faculty of Medicine, and the Life Science Center, ${ }^{\ddagger}$ Tsukuba Advanced Research Alliance, Graduate School of Life and Environmental Sciences, University of Tsukuba, Tsukuba, Japan; the Division of Rheumatology, ${ }^{\dagger}$ Department of Internal Medicine, Kanazawa Graduate School of Medicine, Kanazawa, Japan; the Laboratory of Molecular Biology, ${ }^{\S}$ Center for Cancer Research, National Cancer Institute, $\mathrm{NIH}$, Bethesda, Maryland; and the Department of Internal Medicine, ${ }^{\top}$ Institute of Medical Science, Tokai University School of Medicine, Isehara, Japan

Accepted for publication April 16, 2015.

Address correspondence to Michio Nagata, M.D., Ph.D., Department of Kidney and Vascular Pathology, Faculty of Medicine, University of Tsukuba, 1-1-1 Tennodai, Tsukuba, Ibaraki 305-8575, Japan. E-mail: nagatam@md.tsukuba. ac.jp.

\begin{abstract}
Intracapillary foam cell infiltration with podocyte alterations is a characteristic pathology of focal segmental glomerulosclerosis (FSGS). We investigated the possible role of podocyte injury in glomerular macrophage and foam cell infiltration in a podocyte-selective injury model (NEP25 mice) and hypercholesterolemic model [lowdensity lipoprotein receptor deficiency $\left(L D L R^{-/-}\right)$mice] with doxorubicin-induced nephropathy. Acute podocyte selective injury alone failed to induce glomerular macrophages in the NEP25 mice. However, in the doxorubicin-treated hypercholesterolemic $L D L R^{-/-}$mice, glomerular macrophages/foam cells significantly increased and were accompanied by lipid deposition and the formation and ingestion of oxidized phospholipids (oxPLS). Glomerular macrophages significantly correlated with the amount of glomerular oxPL. The NEP25/LDLR ${ }^{-/-}$mice exhibited severe hypercholesterolemia, glomerular lipid deposition, and renal dysfunction. Imaging mass spectrometry revealed that a major component of oxidized low-density lipoprotein, lysophosphatidylcholine 16:0 and 18:0, was present only in the glomeruli of NEP25/LDLR ${ }^{-/-}$mice. Lysophosphatidylcholine 16:0 stimulated mesangial cells and macrophages, and lysophosphatidylcholine 18:0 stimulated glomerular endothelial cells to express adhesion molecules and chemokines, promoting macrophage adhesion and migration in vitro. In human FSGS, glomerular macrophage-derived foam cells contained oxPLs accompanied by the expression of chemokines in the tuft. In conclusion, glomerular lipid modification represents a novel pathology by podocyte injury, promoting FSGS. Podocyte injury-driven lysophosphatidylcholine de novo accelerated glomerular macrophage-derived foam cell infiltration via lysophosphatidylcholine-mediated expression of adhesion molecules and chemokines in glomerular resident cells. (Am J Pathol 2015, 185: 2118-2131; http://dx.doi.org/10.1016/j.ajpath.2015.04.007)
\end{abstract}

Focal segmental glomerulosclerosis (FSGS) is a progressive kidney disease caused by podocyte injury. ${ }^{1-4}$ The pathology of FSGS includes a variety of glomerular features. The Columbia classification system divides FSGS into the following five variants: not otherwise specified, perihilar variant, cellular variant, tip variant, and collapsing variant. ${ }^{1,5,6}$ The classification is useful for predicting the prognosis in FSGS. ${ }^{1,5-7}$

Glomerulosclerosis is defined by its pathological characteristics, including capillary collapse accompanied by deposition of extracellular matrices and/or hyaline materials. This classic feature of sclerosis is usually observed in not otherwise specified and perihilar variants, whereas it is not observed in the definition of other variants. To diagnose FSGS in the absence of classic sclerosis, the infiltration of foam cells in the glomerular segment is a good marker, particularly in cellular variants. ${ }^{1,7}$ Although glomerular foam cells can be observed in any variant of FSGS and are thought to be involved in disease progression, the mechanism underlying foam cell infiltration in FSGS remains largely unknown.

\footnotetext{
Supported by the NIH Intramural Research Program, National Cancer Institute, Center for Cancer Research (I.P.), Japan Society for the Promotion of Science grants in aid for scientific research projects 22590877 and 26461210, and Ministry of Health, Labor, and Welfare of Japan Progressive Renal Disease Research.

Disclosures: None declared.
} 
Studies have shown that glomerular foam cells were associated with extremely high levels of serum lipids in patients with familial hypercholesterolemia and lecithin-cholesterol acyltransferase deficiency. ${ }^{8,9}$ Glomerular foam cells were also observed in experimental models of hypercholesterolemia, ${ }^{10-15}$ suggesting that high levels of serum lipids may be a plausible basis for glomerular foam cell infiltration. Some studies reported that glomerular foam cells were associated with nephrotic syndrome in humans, including membranous glomerulonephritis, diabetic nephropathy, and IgA glomerulonephritis. ${ }^{16-18}$ However, in these cases, the glomerular foam cells were not always associated with hyperlipidemia. A previous study demonstrated that glomerular foam cells were not correlated with serum cholesterol levels in FSGS patients. ${ }^{7}$ Likewise, glomerular foam cells were absent in minimal change disease, despite the presence of similar levels of serum lipids observed in FSGS. ${ }^{19}$ These findings suggest that additional factors other than serum lipid levels may account for the formation of glomerular foam cells in FSGS.

The characteristic histology of glomerular foam cell formation in FSGS is its segmental and intracapillary localization associated with overlaying podocyte abnormalities. Because podocyte injury represents the common basis of FSGS, there may be a causal relationship between podocyte injury and foam cell accumulation in particular variants of FSGS.

Most glomerular foam cells are derived from CD68-positive macrophages, ${ }^{20,21}$ which transform into foam cells by ingesting lipids within the glomerulus in situ. As demonstrated in the mechanism of atherosclerosis, it seems that the development of glomerular foam cell infiltration in FSGS is because of the interaction and catenation of several factors, including the extent and duration of hyperlipidemia, lipid characteristics, and the response of glomerular resident cells. ${ }^{22-24}$

The present study assessed the stepwise development of glomerular foam cell infiltration using transgenic murine models of FSGS, with podocyte-specific injury and hypercholesterolemia caused by low-density lipoprotein receptor $(L D L R)$ deficiency. We performed imaging mass spectrometry (IMS) analysis to determine the biochemical characteristics of glomerular lipid peroxidation and conducted an in vitro study to assess changes in the molecular profiles of mesangial cells and endothelial cells in response to podocyte injury-driven lipid modifications. Our results suggest that podocyte injury promotes hypercholesterolemia-based lipid deposition and specific peroxidation, which activate a molecular network within a glomerular microenvironment that induces macrophage recruitment and foam cell formation in FSGS.

\section{Materials and Methods}

\section{Animal Experiments}

\section{NEP25 Mice}

NEP25 mice (C57BL/6 background) genetically expressing human CD25 in podocytes were used. ${ }^{3,4,25}$ In this model, injection of the immunotoxin for human CD25 (LMB2) provokes podocyte-specific injury. Because LMB2 does not damage mouse CD25 but human CD25, LMB does not affect any other organs, including the immune system, except for kidney in mice. Mice aged between 8 and 12 weeks were i.v. injected with LMB2 [4 ng/g body weight (BW) diluted in 100 $\mu \mathrm{L}$ of phosphate-buffered saline (PBS) containing $0.1 \%$ bovine serum albumin] or vehicle (VH) through the tail vein. The mice died approximately 2 weeks later because of severe nephrosis. The mice were perfused after 12 days, and kidney tissues were obtained. The LMB2-treated mice $(n=5)$ were histologically compared with the VH-treated control mice $(n=4)$.

$L D L R^{-/-}$Mice

$L D L R$ knockout $\left(L D L R^{-1-}\right)$ mice (C57BL/6 background) were used in a hypercholesterolemic mouse model. ${ }^{26}$ Male mice aged between 8 and 12 weeks underwent uninephrectomy of the right kidney under anesthesia using 30\% isoflurane (Wako, Osaka, Japan) and were fed a high-fat diet (HFD; $42.6 \%$ kcal from fat; Harlan Laboratories, Indianapolis, IN) or a normal diet (ND). Because the genetic background of the $L D L R^{-/-}$mice revealed low susceptibility to doxorubicin [Adriamycin (ADR); Sigma-Aldrich, St. Louis, MO]-induced nephropathy, ${ }^{27}$ uninephrectomy was performed before the ADR treatment. After 1 week of uninephrectomy, the mice were injected twice with i.v. ADR or $\mathrm{VH}$ through the tail vein. ADR was dissolved with ultrapure water and diluted with $0.9 \% \mathrm{NaCl}$ (final concentration, 2 $\mathrm{mg} / \mathrm{mL}$ ); $0.9 \% \mathrm{NaCl}$ was used as a $\mathrm{VH}$, with the volume equivalent to the ADR solution. The dose of ADR was 15 $\mathrm{mg} / \mathrm{kg} \mathrm{BW}$ on day 0 and $20 \mathrm{mg} / \mathrm{kg} \mathrm{BW}$ on day 14 . The mice were perfused on day 42 , and serum and kidney tissues were obtained. The experimental animal groups were as follows: $\mathrm{ADR}+\mathrm{ND} / L D L R^{-/-}$(ADR-treated $L D L R^{-/-}$fed a ND), $\mathrm{ADR}+\mathrm{HFD} / L D L R^{-1-}$ (ADR-treated $L D L R^{-1-}$ fed a HFD), and $\mathrm{VH}+\mathrm{HFD} / L D L R^{-/-}$(VH-treated $L D L R^{-/-}$fed a HFD).

\section{NEP25/LDLR ${ }^{-/-}$Double-Transgenic Mice}

By crossing the $L D L R^{-1-}$ mice with the NEP25 mice, NEP25/ $L D L R^{-1-}$ double-transgenic mice were generated. In this model, the LMB2 injection provokes podocyte-specific injury, together with hypercholesterolemia induced by the HFD. Male mice were initially maintained on an ND. The mice aged between 8 and 12 weeks were then fed a HFD or an ND. After 4 weeks of feeding, $100 \mu \mathrm{L}$ of LMB2 (4 ng/g BW in PBS containing $0.1 \%$ bovine serum albumin) or $100 \mu \mathrm{L}$ of $\mathrm{VH}$ was injected i.v. through the tail vein. The mice were sacrificed after 12 days, and serum and kidney tissues were obtained. On the same day, 24-hour urine was also collected. Kidney tissues were used for histochemical or matrix-assisted laser desorption/ deionization time-of-flight IMS (MALDI-TOF-IMS) analysis. We compared the LMB2 + HFD/NEP25/LDLR ${ }^{-1-}$ mice (LMB2-treated NEP25/LDLR ${ }^{-1-}$ mice fed a HFD) with the $\mathrm{VH}+\mathrm{HFD} / L D L R^{-1-}$ mice (VH-treated $L D L R^{-1-}$ mice fed a HFD) and the LMB2 + ND/NEP25 mice (LMB2-treated NEP25 mice fed an ND). 
Hara et al

Table 1 Sequences of Primers Used for Quantitative RT-PCR

\begin{tabular}{|c|c|c|}
\hline Gene & Forward primer & Reverse primer \\
\hline GAPDH & 5'-TGGGAAGCTGGTCATCAAC-3' & 5'-GCATCACCCCATTTGATGTT-3' \\
\hline CCL2 (MCP-1) & 5'-AGCATCCACGTGCTGTCTC-3' & 5'-GATCATCTTGCCAGTGAATGAG-3' \\
\hline VCAM1 & 5'-CAAATGGAGTCTGAACCCAAA-3' & 5'-GGTTCTTTCGGAGCAACG-3' \\
\hline ICAM1 & 5'-GCAGACCACTGTGCTTTGAG-3' & 5'-TCCAGCTCCACTCGCTCT-3' \\
\hline SELE & 5'-TCTAAGATGCGAGCAATCAGG-3' & 5'-CAGGATTCTGCAGACAGTTCA-3' \\
\hline SELP & $5^{\prime}-\mathrm{AATCCCCCGCAGTGTAAAG-3^{ \prime }}$ & 5'-GGGTGTGTACAGTCCATGGTT-3' \\
\hline MIF & $5^{\prime}-$ TGCCAGAGGGGTTTCTCTC-3' & 5'-GCTCGTGCCACTAAAAGTCA-3' \\
\hline CSF1 (M-CSF) & $5^{\prime}$-CAAGGACTATAAGGAACAGAACGAG-3' & 5'-GAAATTCTTGATTTTCTCCAGCA-3' \\
\hline TNFA & $5^{\prime}-\mathrm{GCCCAGACCCTCACACTC-3^{ \prime }}$ & $5^{\prime}$-CCACTCCAGCTGCTCCTCT-3' \\
\hline IL6 & 5'-CCCTTCAGGAACAGCTATGAA-3' & $5^{\prime}-$ ACAACATCAGTCCCAAGAAGG-3' \\
\hline CXCR2 & $5^{\prime}$-CAGAGACTTGGGAGCCACTC- $3^{\prime}$ & 5'-GCTGAAATTATCCACCCTGATT-3' \\
\hline CXCR4 & $5^{\prime}$-GCTGGAGAGCGAGCATTG-3' & 5'-CCTGTTGAAGTTTTCGTTTTCA-3' \\
\hline CCR2 & 5'-AAGAAGTATCCAAGAGCTTGATGAG-3' & $5^{\prime}$-TCACCATCATCATAGTCATACGG-3' \\
\hline CCR4 & $5^{\prime}-$ CAACTCGACCACGTGGAAA-3' & $5^{\prime}-\mathrm{ATGACCAGCCCCAAGACAT-3^{ \prime }}$ \\
\hline ITGB1 & 5'-TTGGGACGGATCTGATGAAT-3' & $5^{\prime}-$ TCCACAAATGAGCCAAAGC - $3^{\prime}$ \\
\hline ITGB2 & $5^{\prime}-$ TCCACAAAAAGTGACCCTTAACT-3' & 5'-CGTCGGAAAGTCACATTGAA-3' \\
\hline ITGB7 & $5^{\prime}-$ TGCATGGTGCAAGCAACT-3' & $5^{\prime}$-GGCCAGTAGCTCCTCACG-3' \\
\hline SELPLG (PSGL-1) & 5'-TTTGCTGGCCATTCTCATCT-3' & $5^{\prime}-\mathrm{CACCACCGTGCACACAAG-3^{ \prime }}$ \\
\hline OLR1 (LOX-1) & 5'-GACTGGATCTGGCATAAAGA-3' & 5'-ССTTСTTCTGACATATGCTG-3' \\
\hline SRA1 & $5^{\prime}$-ATGACAAAGAGAGATGACAGAGAAT-3' & $5^{\prime}$-TTATGAAGTACAAGTGACCCC-3' \\
\hline SRA2 & $5^{\prime}$-GGGAAGCAAGGAGCAGATG-3' & 5'-GTCACCTTTGCTGCCCTTT-3' \\
\hline CD36 & $5^{\prime}$-CAAGAAGCCAAGCTGTAGGG-3' & $5^{\prime}$-CCCAACAGGCTCCTACTCAGC-3' \\
\hline CD68 & 5'-TCTGACCTTGCTGGTACTGC-3' & 5'-GAAGAGTGGCAGCCTTTTTG-3' \\
\hline$A B C A 1$ & 5'-AACAGTTTGTGGCCCTTTTG-3' & $5^{\prime}$-AGTTCCAGGCTGGGGTACTT-3' \\
\hline$A B C G 1$ & 5'-GAAGGTTGCCACAGCTTCTC-3' & $5^{\prime}$-CATGGTCTTGGCCAGGTAGT-3' \\
\hline
\end{tabular}

LOX, lectin-like oxidized low-density lipoprotein receptor; MCP, monocyte chemoattractant protein; M-CSF, monocyte colony-stimulating factor; PSGL, P-selectin glycoprotein ligand.

For animal handling and tissue preparation, all experimental procedures were conducted using protocols approved by the Institutional Animal Care and Use Committee of the University of Tsukuba (Tsukuba, Japan; registration numbers 12-380, 13-186, and 14-359).

\section{Biochemical Analysis}

The following biochemical parameters were measured from serum samples: blood urea, nitrogen, creatinine, total cholesterol, triglycerides, and high-density lipoprotein cholesterol using DRI-CHEM7000 (Fujifilm, Tokyo, Japan). In addition, LDL cholesterol was calculated using the Friedrich formula. ${ }^{28}$ Urine was analyzed for urinary total protein and creatinine using an automated analyzer (SRL, Tokyo, Japan). Proteinuria was determined by the protein/creatinine ratio.

\section{Histochemistry of Renal Sections}

The mice were anesthetized with $30 \%$ isoflurane and perfused through the heart with $4 \%$ paraformaldehyde (Wako). After kidney dissection, tissue was fixed with $4 \%$ paraformaldehyde for paraffin or frozen sections, or with $2 \%$ glutaraldehyde for transmission electron microscopy. Paraffin sections $(2 \mu \mathrm{m}$ thick) were processed for periodic acid-Schiff staining, periodic acid-methenamine-silver staining, and immunostaining of human specimens for CD68, oxidized phospholipid
(oxPL), macrophage migration inhibitory factor (MIF), lectinlike oxidized LDL receptor-1 (LOX-1), and scavenger receptor class B type I (SR-BI). Frozen sections ( $5 \mu \mathrm{m}$ thick) were also processed for oil red $\mathrm{O}$ staining and immunostaining of mouse specimens for Wilms tumor protein-1 (WT-1), CD68, and oxPL. The following specific primary antibodies were used: polyclonal rat anti-mouse CD68 antibody (AbD Serotec, Oxford, UK), monoclonal mouse anti-human CD68 antibody (DakoCytomation, Carpinteria, CA), polyclonal goat anti-mouse WT-1 antibody (Santa Cruz Biotechnology, Dallas, TX), monoclonal mouse anti-mouse/human oxPL antibody (Avanti Polar Lipids, Alabaster, AL), polyclonal rabbit anti-mouse/human MIF antibody (Santa Cruz Biotechnology), polyclonal rabbit anti-mouse/human LOX-1 antibody (Abcam, Cambridge, UK), and polyclonal rabbit anti-mouse/ human SR-BI antibody (Novus Biologicals, Littleton, CO). For immunostaining, antigen retrieval was performed using a microwave (10 mmol/L citrate buffer; $\mathrm{pH}$ 6.0) for WT-1, LOX-1, and SR-BI or proteinase K (Wako) for human CD68 and oxPL. Thereafter, primary antibodies were incubated in a Histofine kit (Nichirei Bioscience, Tokyo, Japan), followed by reaction with peroxidase-conjugated streptavidin (Nichirei Bioscience). Peroxidase activity was visualized using a liquid diaminobenzidine substrate (Dako, Glostrup, Denmark). Hematoxylin was used to stain nuclei. For oil red O staining, $0.3 \mathrm{~g}$ of oil red $\mathrm{O}$ (Santa Cruz Biotechnology) was diluted with $100 \mathrm{~mL}$ of $100 \%$ isopropanol (Wako) and incubated overnight. 
Table 2 Serological Analysis in the Doxorubicin Nephropathy Model in $L D L R^{-/-}$Mice

\begin{tabular}{|c|c|c|c|}
\hline Variable & $\begin{array}{l}\mathrm{ADR}+\mathrm{ND} / L D L R^{-/-} \\
\text {mice }(n=4)\end{array}$ & $\begin{array}{l}\mathrm{VH}+\mathrm{HFD} / L D L R^{-/-} \\
\text {mice }(n=5)\end{array}$ & $\begin{array}{l}\mathrm{ADR}+\mathrm{HFD} / \mathrm{LDLR}^{-/-} \\
\text {mice }(n=4)\end{array}$ \\
\hline T cholesterol (mg/dL) & $285 \pm 73$ & $1794 \pm 139 *$ & $1540 \pm 322^{*}$ \\
\hline HDL cholesterol (mg/dL) & $113 \pm 48$ & $160 \pm 29$ & $160 \pm 45$ \\
\hline LDL cholesterol (mg/dL) & $156 \pm 28$ & $1558 \pm 158^{*}$ & $1332 \pm 278^{*}$ \\
\hline Blood urea nitrogen $(\mathrm{mg} / \mathrm{dL})$ & $111 \pm 21$ & $39 \pm 4^{*}$ & $67 \pm 15$ \\
\hline
\end{tabular}

${ }^{*} P<0.05$ vs ADR $+\mathrm{ND} / L D L R^{-/-}$mice.

ADR, Adriamycin (doxorubicin); HDL, high-density lipoprotein; HFD, high-fat diet; LDL, low-density lipoprotein; LDLR, LDL receptor; ND, normal diet; T cholesterol, total cholesterol; VH, vehicle.

The $0.3 \%$ oil red $\mathrm{O}$ solution was diluted with ultrapure water to yield $0.05 \%$ oil red $\mathrm{O}$ solution. After section incubation with $60 \%$ isopropanol for 1 minute, the section was stained with $0.05 \%$ of oil red $\mathrm{O}$ solution for 10 minutes. To measure the oil red $\mathrm{O}$-positive area in the glomeruli, the Lumina Vision imaging software package version 2.4.4 (Mitani Cooperation, Osaka, Japan) was used. The oil red O-positive ratio was calculated by dividing the oil red $\mathrm{O}-$ positive area by the glomerular tuft area. The glomerular count was 50 to 100 per animal.

\section{MALDI-TOF-IMS Analysis}

Male LMB2 + HFD/NEP25/LDLR ${ }^{-/-}(n=3), \mathrm{VH}+\mathrm{HFD} /$ $L D L R^{-1-}(n=4)$, and LMB2 $+\mathrm{ND} / \mathrm{NEP} 25$ mice $(n=4)$ were used for MALDI-TOF-IMS. The animals were anesthetized using 30\% isoflurane, and the kidneys were then resected and immediately frozen using dry ice powder. The frozen tissues were sliced into sections $\left(10 \mu \mathrm{m}\right.$ thick) at $-17^{\circ} \mathrm{C}$ and placed onto $0.1 \%$ poly-L-lysine (Sigma-Aldrich)-coated MALDI indium-tin oxide-coated slides (Bruker Daltonics, Bremen, Germany). The sections were dehydrated in a desiccator for 40 minutes and stored at $-80^{\circ} \mathrm{C}$ until use. The matrix solution was subsequently prepared using $10 \mathrm{mg} / \mathrm{mL}$ of 2,5-dihydroxybenzoic acid (Wako) in 50\% methanol (Wako). Then, $0.2 \%$ of trifluoroacetic acid (Wako) was added as an ion-pairing agent. A 2-mL matrix solution was sprayed onto each tissue section using Imageprep (Bruker Daltonics). For the MALDI-TOF-IMS analysis, both profiling and IMS experiments on tissue sections were performed using an Ultraflex MALDI MS instrument (Bruker Daltonics). In the IMS experiments, a 0 to 2000 mass/charge ratio $(\mathrm{m} / \mathrm{z})$ region was selected in positive-ionization modes by averaging 500 consecutive laser shots per pixel. The spatial resolution for the imaging data was $80 \mu \mathrm{m}$. The laser energy was set at 55\% (5.5 $\mu \mathrm{J})$, with a repetition rate of $100 \mathrm{~Hz}$. Mass calibration was performed using peptide calibration standard II (Bruker Daltonics) before data acquisition. The raster scan was performed automatically. Software obtained from Bruker Daltonics (flexImaging version 2.1 and flexAnalysis version 3.3) was used for the data analysis. The ion intensities for each $\mathrm{m} / \mathrm{z}$ value were normalized using flexImaging software, and all spectral intensities were divided by the obtained total ion count value. The ion intensities were evaluated by comparing ion pairs from glomeruli and background normal tissue on the same section after normalization. Candidate lipids were identified using lipid databases, such as LIPIDMAPS (http://www. lipidmaps.org/tools/ms/LMSD_search_mass_options.php, last accessed April 15, 2015). Finally, MS/MS analysis was performed to confirm the chemical structure of the selected lipid of interest using the lipid standards for lysophosphatidylcholine (LPC) 16:0 and 18:0 (both Avanti Polar Lipids). To recognize the location of glomeruli in heat map images of MALDI-TOF-IMS, we used hematoxylin and eosin staining in the same section that was used for measurement of MALDITOF-IMS. Briefly, after we performed MALDI-TOF-IMS measurement, we stained the same section for hematoxylin and eosin staining and then recognized the location of glomeruli and depicted as white circles. Finally, we mixed the white circles with heat map images. Our method is a modified version of previous studies. ${ }^{29,30}$

\section{Cultured Rat Glomerular Endothelial Cells and Mesangial Cells}

Rat glomerular endothelial cells (GEnCs) and mesangial cells were provided by Dr. Masaomi Nangaku (University of Tokyo School of Medicine, Tokyo, Japan) and Dr. Shuji Kondo (Tokushima University, Tokushima, Japan), respectively. ${ }^{31,32}$ For propagation of the GEnCs, the cells were cultured on a noncoated 10-cm dish (Corning, Corning, NY) at $37^{\circ} \mathrm{C}$. The medium used consisted of RPMI-1640 (Biochrom, Berlin, Germany), containing $10 \%$ fetal bovine serum (PAA, Pasching, Austria), 10\% Nu-serum (BD Biosciences, Bedford, MA), and $1 \%$ penicillin-streptomycin (Sigma-Aldrich). ${ }^{31}$ For propagation of the mesangial cells, the cells were cultured on a noncoated $10-\mathrm{cm}$ dish at $37^{\circ} \mathrm{C}$. The medium used consisted of RPMI 1640 medium with $10 \%$ fetal bovine serum, $10 \mathrm{mmol} / \mathrm{L}$ of HEPES buffer (Sigma-Aldrich), $2 \mathrm{mmol} / \mathrm{L}$ of L-glutamine (SigmaAldrich), and $1 \%$ penicillin-streptomycin. ${ }^{32}$ For each cell line, cells at passages 8 to 22 were used in the experiments.

\section{Total RNA Extraction and Quantitative RT-PCR Analysis}

Total RNA was extracted using the RNeasy Mini Kit (Qiagen, Hilden, Germany). RNA was quantified using a 
A
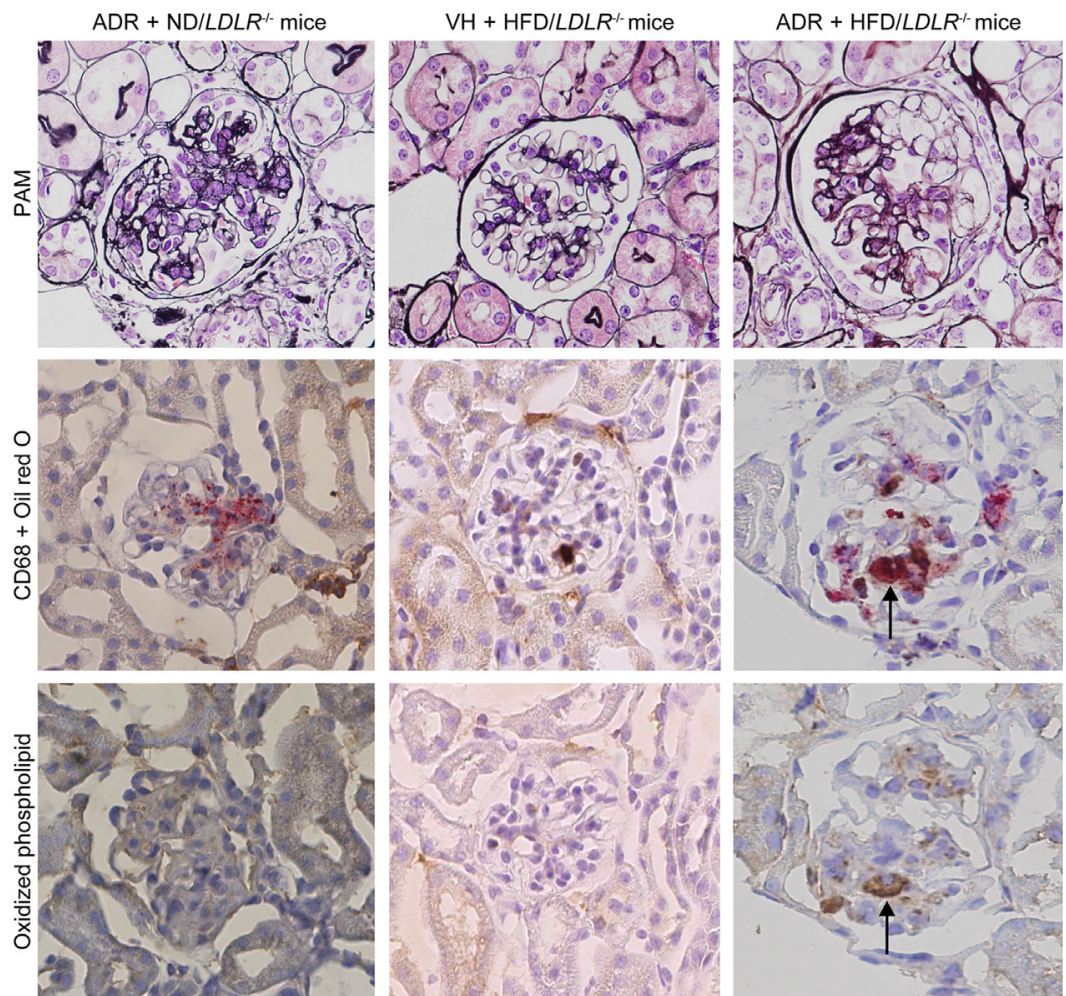

B
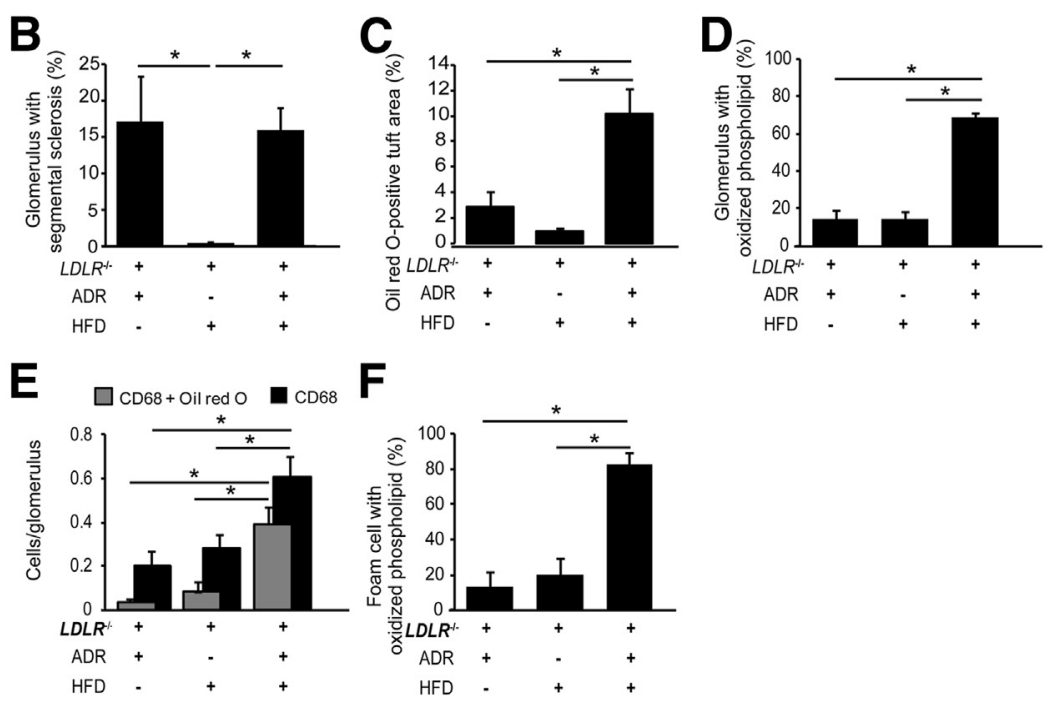

$F$

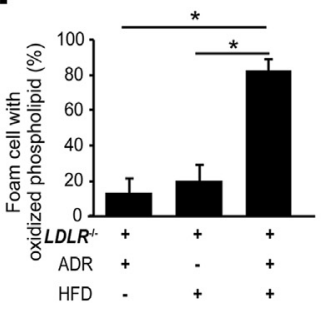

Figure 1 Doxorubicin [Adriamycin (ADR)] nephropathy in uninephrectomized low-density lipoprotein receptor deficiency $\left(L D L R^{-/-}\right)$mice promotes hypercholesterolemia-mediated macrophage-derived foam cell infiltration in the glomerulus. A: Periodic acid-silver methenamine (PAM) staining reveals segmental glomerulosclerosis in the ADR + high-fat diet (HFD)/LDLR ${ }^{-/-}$and ADR + normal diet (ND)/ $L D L R^{-/-}$mice. Glomerular foam cell infiltration is observed only in the ADR + HFD/LDLR ${ }^{-/-}$mice. CD68 (brown) and oil red 0 (red) double staining reveals macrophage-derived foam cell infiltration (arrow, $\mathrm{CD} 68+$ Oil red 0) in the glomeruli of the ADR + HFD/ $L D L R^{-/-}$mice, accompanied by oil red 0 -positive lipid deposition. Oxidized phospholipid (oxPL) colocalizes with either oil red 0 -positive lipids or macrophage-derived foam cells (arrow, 0xidized phospholipid). B: Glomeruli exhibiting segmental glomerulosclerosis significantly increases in the $\mathrm{ADR}+\mathrm{HFD} / \mathrm{LDLR}^{-/-}$and $\mathrm{ADR}+\mathrm{ND} / L D L R^{-/-}$mice compared with the vehicle (VH) $+\mathrm{HFD} / L D L R^{-/-}$ mice. C: The intraglomerular oil red $0-$ positive lipid content significantly increases in the ADR + HFD/ $L D L R^{-/-}$mice versus the $\mathrm{ADR}+\mathrm{ND} / L D L R^{-/-}$and $\mathrm{VH}+\mathrm{HFD} / L D L R^{-/-}$mice. D: The ratio of glomeruli with oxPL deposition significantly increases in the $\mathrm{ADR}+\mathrm{HFD} / L D L R^{-/-}$mice compared with the $\mathrm{ADR}+\mathrm{ND} / L D L R^{-/-}$and $\mathrm{VH}+\mathrm{HFD} / L D L R^{-/-}$mice. E: The infiltration of macrophages and macrophagederived foam cells elevates significantly in the $\mathrm{ADR}+\mathrm{HFD} / L D L R^{-/-}$mice compared with the $\mathrm{ADR}+\mathrm{ND} / L D L R^{-/-}$and $\mathrm{VH}+\mathrm{HFD} / L D L R^{-/-}$mice. F: The ratio of macrophage-derived foam cells containing oxPL significantly increases in the ADR + HFD/ $L D L R^{-/-}$mice compared with the $\mathrm{ADR}+\mathrm{ND} / L D L R^{-/-}$ and $\mathrm{VH}+\mathrm{HFD} / L D L R^{-/}$mice. $n=5(\mathbf{A}-\mathbf{F}$, $\mathrm{ADR}+\mathrm{HFD} / L D L R^{-/-}$mice and $\mathrm{VH}+\mathrm{HFD} / L D L R^{-/}$ mice) $; n=4\left(\mathbf{A}-\mathbf{F}, \mathrm{ADR}+\mathrm{ND} / \mathrm{LDLR}^{-/-}\right.$mice). ${ }^{*} P<0.05$. Original magnification, $\times 400(A)$.
Nanodrop 1000 spectrophotometer (Thermo Scientific, Rockford, IL). Total RNA $(1 \mu \mathrm{g})$ was reverse transcribed using the Thermoscript RT-PCR System (Life Technologies, Tokyo, Japan) for first-strand cDNA. Subsequently, 10 ng of cDNA template and $0.25 \mathrm{mmol} / \mathrm{L}$ of sequence-specific primers were used for RT-PCR. All of the measured values were normalized with glyceraldehyde-3-phosphate dehydrogenase and calculated according to the $\Delta \Delta C T$ method. For quantitative RT-PCR (RT-qPCR) of the GEnCs and mesangial cells, the cells were incubated with RPMI 1640 medium containing $0.02 \%$ bovine serum albumin (SigmaAldrich) for 24 hours. LPC 16:0 or 18:0 was then added to the dishes at a final concentration of $10 \mu \mathrm{g} / \mathrm{mL}$. Our preliminary experiment and other studies confirmed that this concentration was appropriate to stimulate mesangial cells and GEnCs because $>25 \mu \mathrm{g} / \mathrm{mL}$ of LPC is known to be cytotoxic. ${ }^{33-35}$ The LPCs were diluted with $99.5 \%$ ethanol (Wako). The final concentration of ethanol in the dishes was $<0.5 \%$. The same volume of ethanol was added as a control. Total RNA was extracted at 8 hours for mesangial cells and at 12 hours for GEnCs, after the addition of LPCs or the control. cDNA was then generated for RT-qPCR. For the RT-qPCR of rat peritoneal macrophage and mesangial cell/ GEnC co-culture, total RNA was extracted using adherent macrophages on LPC- or control-treated mesangial cells/ GEnCs. cDNA was then generated for RT-qPCR. For the 
Table 3 Serological Analysis in the NEP25/LDLR $R^{-/-}$Mouse Model

\begin{tabular}{lccc}
\hline & $\begin{array}{l}\mathrm{LMB} 2+\mathrm{ND} / \mathrm{NEP} 25 \\
\text { Variable }\end{array}$ & $\begin{array}{l}\mathrm{VH}+\mathrm{HFD} / \mathrm{LDLR} R^{-/-} \\
\text {mice }(n=7)\end{array}$ & $\begin{array}{l}\mathrm{LMB2}+\mathrm{HFD} / \mathrm{NEP} 25 / L D L R^{-/-} \\
\text {mice }(n=8)\end{array}$ \\
\hline T cholesterol $(\mathrm{mg} / \mathrm{dL})$ & $523 \pm 96$ & $2147 \pm 171^{*}$ & $6433 \pm 1322^{* \dagger}$ \\
Triglycerides $(\mathrm{mg} / \mathrm{dL})$ & $372 \pm 130$ & $203 \pm 36$ & $594 \pm 135$ \\
$\mathrm{HDL}$ cholesterol $(\mathrm{mg} / \mathrm{dL})$ & $299 \pm 56$ & $244 \pm 12$ & $511 \pm 76$ \\
LDL cholesterol $(\mathrm{mg} / \mathrm{dL})$ & $150 \pm 103$ & $1862 \pm 161^{*}$ & $5826 \pm 1274^{*}$ \\
Blood urea nitrogen $(\mathrm{mg} / \mathrm{dL})$ & $86 \pm 14$ & $32 \pm 1^{*}$ & $322 \pm 76^{* \dagger}$ \\
Creatinine $(\mathrm{mg} / \mathrm{dL})$ & $0.46 \pm 0.16$ & $0.11 \pm 0.01$ & $2.63 \pm 0.77^{* \dagger}$ \\
Urinary protein/creatinine $(\mathrm{g} / \mathrm{g})$ & $227 \pm 48$ & $2.4 \pm 0.3^{*}$ & $148 \pm 34^{\dagger}$ \\
\hline
\end{tabular}

${ }^{*} P<0.05$ vs $L M B 2+$ ND/NEP25 mice.

${ }^{\dagger} P<0.05$ vs $\mathrm{VH}+\mathrm{HFD} / \mathrm{LDLR}^{-1-}$ mice.

HDL, high-density lipoprotein; HFD, high-fat diet; LDL, low-density lipoprotein; LDLR, LDL receptor; ND, normal diet; T cholesterol, total cholesterol; VH, vehicle.

RT-qPCR of rat peritoneal macrophages, macrophages were incubated with $10 \mu \mathrm{g} / \mathrm{mL}$ of LPC- or control-containing medium. After 48 hours' incubation, total RNA was extracted and then cDNA was generated for RT-qPCR. The primer sequences are described in Table 1.

\section{Western Blot Analysis}

Proteins from the cultured GEnCs or mesangial cells were extracted and solubilized in radioimmunoprecipitation assay buffer with protease inhibitors. The proteins were separated by $4 \%$ to $12 \%$ SDS-PAGE and transferred to polyvinylidene difluoride membranes (GE Healthcare Japan, Tokyo, Japan). Blots were incubated with the following primary antibodies: polyclonal rabbit anti-rat monocyte chemoattractant protein-1 (MCP-1) antibody (Abcam, Cambridge, UK) and polyclonal rabbit anti-rat MIF antibody (Santa Cruz Biotechnology). After washing in blocking solution, primary antibodies were detected using a horseradish peroxidase-conjugated antibody (GE Healthcare Japan) and a chemiluminescent substrate (Thermo Scientific). Protein expression was assessed by Western blot analysis, normalized to $\alpha$-tubulin (SigmaAldrich) for GEnCs or $\beta$-actin (Sigma-Aldrich) for mesangial cells.

\section{Extraction of Rat Peritoneal Macrophages}

A male Sprague-Dawley rat (200 to $450 \mathrm{~g} \mathrm{BW}$ ) was anesthetized with $30 \%$ isoflurane, and total blood was collected from the cervical artery. Subsequently, $30 \mathrm{~mL}$ of ice-cold RPMI 1640 medium was infused i.p. and washed three times. The lavage was then extracted and centrifuged for 5 minutes at $500 \times g$. The pellet was washed twice with ice-cold RPMI 1640 medium. The pellet was resuspended in RPMI 1640 medium containing $10 \%$ of fetal bovine serum, $2 \mathrm{mmol} / \mathrm{L}$ of L-glutamine, $10 \mathrm{mmol} / \mathrm{L}$ of HEPES buffer, $1 \%$ of minimum essential media nonessential amino acid solution (Wako), and $1 \%$ penicillin-streptomycin, and then incubated at $37^{\circ} \mathrm{C} .{ }^{36}$ After 6 hours of incubation, nonadherent cells were removed by washing three times with PBS. After a further 48 hours of incubation, the macrophages were used for RT-qPCR, adhesion, and migration assays. The collected cells were histologically confirmed as macrophages using Wright staining.

\section{Macrophage Adhesion and Migration Assay}

For the macrophage adhesion assay, rat peritoneal macrophages $\left(1 \times 10^{6}\right)$ were added to LPC- or control-treated GEnCs or mesangial cells, and incubated for 30 minutes at $37^{\circ} \mathrm{C}$. Nonadherent macrophages were removed by washing twice with PBS. Adherent macrophages were then counted at 10 random sites (magnification, $\times 100$ ). For the macrophage migration assay, Boyden chambers $(8-\mu \mathrm{m}$ pore size; Corning) were used. The lower surfaces of the membrane filters were coated with collagen type IV (BD Biosciences). The following three different mediums were applied in the lower column: i) $1 \mathrm{~mL}$ of RPMI 1640 medium with or without LPC 16:0 or 18:0, ii) $1 \mathrm{~mL}$ of supernatants from the LPC- or control-treated GEnC/mesangial cells, and iii) $1 \mathrm{~mL}$ of supernatants from the LPC- or control-treated GEnC/mesangial cells, in addition to MCP-1 or MIF blockade. Blockade of MCP-1 and MIF was performed by adding $5 \mu \mathrm{g} / \mathrm{mL}$ of MCP-1 neutralizing antibody (BioLegend, San Diego, CA) or $100 \mu \mathrm{mol} / \mathrm{L}$ of 4-iodo-6phenylpyrimidine (Tocris Bioscience, Bristol, UK). ${ }^{37,38}$ Subsequently, $100 \mu \mathrm{L}$ of a suspension of rat peritoneal macrophages $\left(1 \times 10^{5}\right)$ was seeded onto the top of a chamber and allowed to migrate for 2 hours at $37^{\circ} \mathrm{C}$. The membrane was fixed in $4 \%$ paraformaldehyde for $10 \mathrm{mi}-$ nutes and stained with hematoxylin for 30 minutes. The upper membrane surface was wiped using a cotton swab to remove nonmigrated macrophages. Migrated macrophages on the lower membrane surface were counted at 10 random sites (magnification, $\times 200$ ).

\section{Statistical Analysis}

The Tukey-Kramer test, performed using StatView-J version 5.0 (Adept Scientific, Acton, MA), was used to compare 


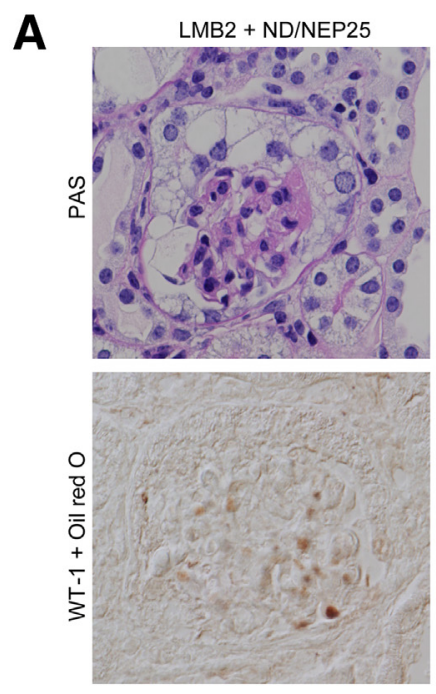

B
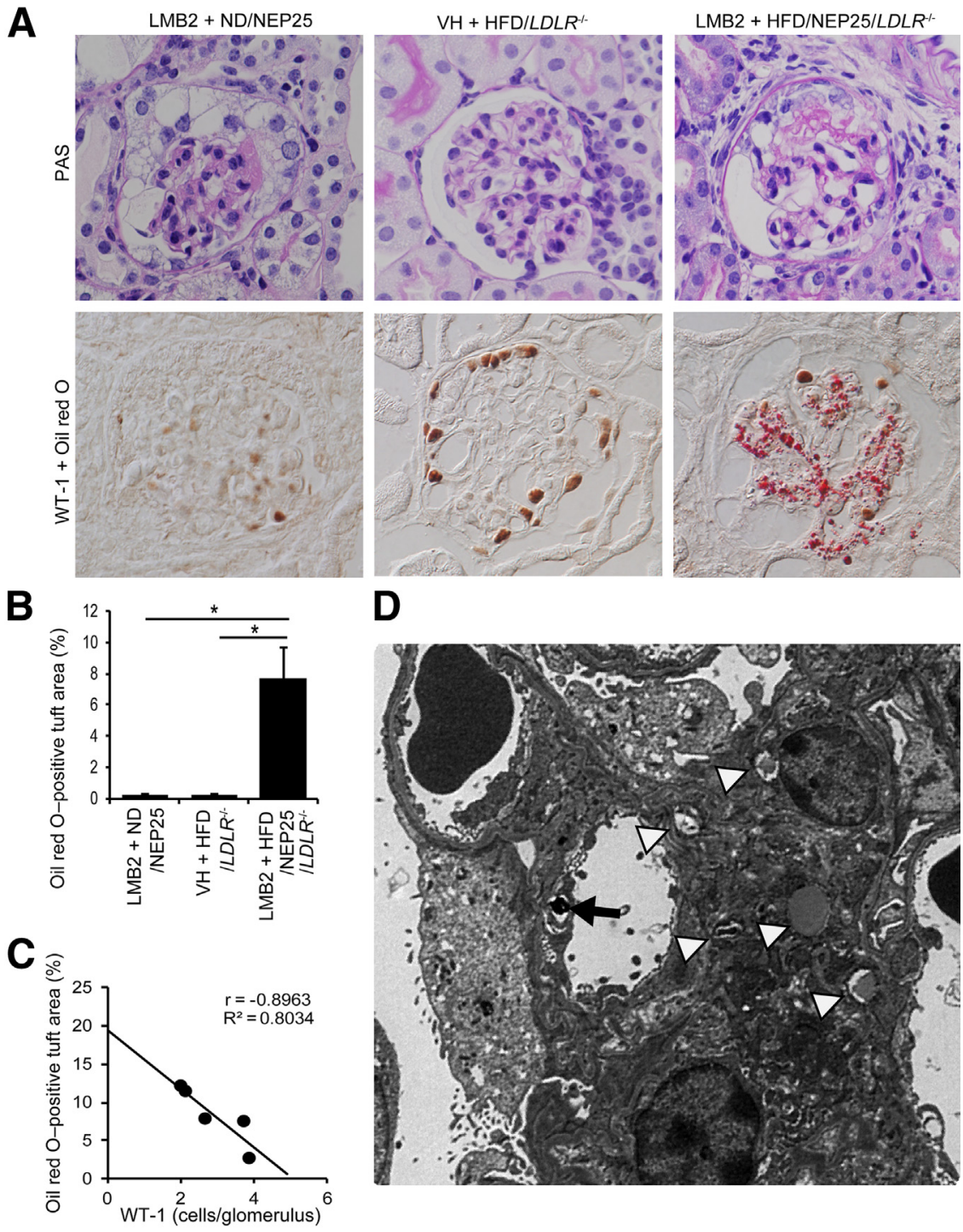

\section{D}

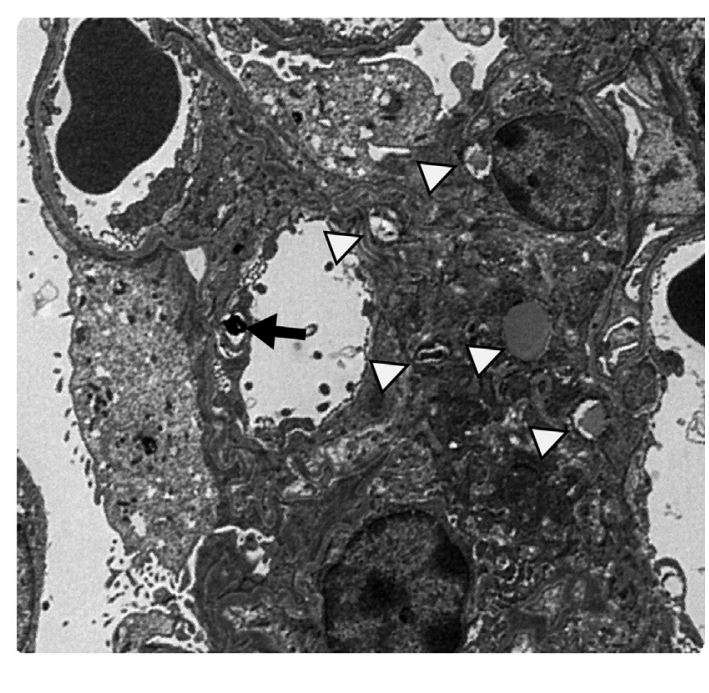

Figure 2 NEP25/low-density lipoprotein receptor deficiency $\left(L D L R^{-/-}\right)$double-transgenic mice exhibit aberrant glomerular lipid deposition, which correlates with podocyte loss. A: Periodic acid-Schiff (PAS) staining reveals diffuse glomerular tuft collapse, with epithelial hyperplasia, in the LMB2 + high-fat diet (HFD)/NEP25/LDLR ${ }^{-/}$and LMB2 + normal diet (ND)/NEP25 mice; glomeruli in the vehicle $(\mathrm{VH})+\mathrm{HFD} / L D L R^{-/-}$mice are not affected. Double labeling with Wilms tumor protein-1 (WT-1; brown) and oil red 0 (red) reveals severe glomerular oil red 0 -positive lipid deposition, accompanied by WT-1-positive podocyte loss, in the LMB2 + HFD/ NEP25/LDLR ${ }^{-/-}$mice. Neither the LMB2 + ND/ NEP25 nor the VH + HFD/LDLR ${ }^{-/-}$mice exhibit oil red 0-positive lipid deposition. B: The glomerular oil red 0 -positive lipid content significantly increases in the LMB2 + HFD/NEP25/LDLR ${ }^{-/-}$mice compared with the LMB2 + ND/NEP25 and VH + HFD/LDLR ${ }^{-/}$ mice. C: Regression analysis reveals that the oil red 0 positive lipid area inversely correlates with the number of WT-1-positive podocytes in the LMB2 + HFD/NEP25/LDLR ${ }^{-/-}$mice. Between 50 and 70 glomeruli were counted per mouse. D: Transmission electron microscopy reveals that lipid droplets accumulate in the mesangial (arrowheads) and glomerular endothelial cells (arrow) in the LMB2 + HFD/ NEP25/LDLR ${ }^{-/-}$mice. Lipid droplets are absent in podocytes. $n=5$ (B, LMB2 + HFD/NEP25/LDLR ${ }^{-/-}$, LMB2 + ND/NEP25, and VH + HFD/LDLR ${ }^{-/}$mice, and D). ${ }^{*} P<0.05$. Original magnifications: $\times 400$ (A); $\times 2000($ C). parametric values among three or more groups. A two-tailed $t$-test was used to compare parametric values between two groups. The data are provided as means \pm SEM. $P<0.05$ was considered statistically significant.

\section{Results}

\section{Acute Podocyte Injury Fails to Induce Macrophage Recruitment}

The LMB2-treated NEP25 mice exhibited severe nephrosis with diffuse tuft collapse accompanied by epithelial hyperplasia on day 12 , as we have already reported in this model. ${ }^{25}$ Immunostaining for CD68 revealed a minimal number of macrophage influx in both the LMB2-treated NEP25 mice and the controls, without statistical significance $(0.038 \pm 0.012$ versus $0.021 \pm 0.007$ cells/glomerulus; $P=0.24)$. This suggests that acute podocyte injury alone is insufficient to induce macrophages into glomeruli, even when accompanied by severe, but short-term, nephrosis.
Doxorubicin Nephropathy with Hypercholesterolemia Promotes Foam Cell Infiltration via Lipid Peroxidation

To test whether podocyte injury induced glomerular macrophages and foam cell infiltration in the context of prolonged or marked hypercholesterolemia, ADR nephropathy was induced in the $L D L R^{-1-}$ mice. The $\mathrm{ADR}+\mathrm{HFD} / L D L R^{-1-}$ mice and $\mathrm{VH}+\mathrm{HFD} / L D L R^{-1-}$ mice exhibited similar levels of severe hypercholesterolemia, characterized by elevation of LDL cholesterol, whereas the ADR $+\mathrm{ND} / L D L R^{-1-}$ mice lacked such hypercholesterolemia (Table 2). In histology, the ADR + HFD/ $L D L R^{-1-}$ mice and ADR + ND/LDLR ${ }^{-1-}$ mice exhibited a similar number of FSGS lesions, despite the absence of FSGS in the VH $+\mathrm{HFD} / L D L R^{-1-}$ mice (Figure 1, A and B). The amount of glomerular lipid deposition, as revealed by the oil red $\mathrm{O}-$ positive area, and the incidence of glomeruli with oxPL were significantly higher in the ADR + HFD/ $L D L R^{-1-}$ mice than the other groups (Figure 1, C and D). In addition, glomeruli with CD68-positive macrophages and 
A
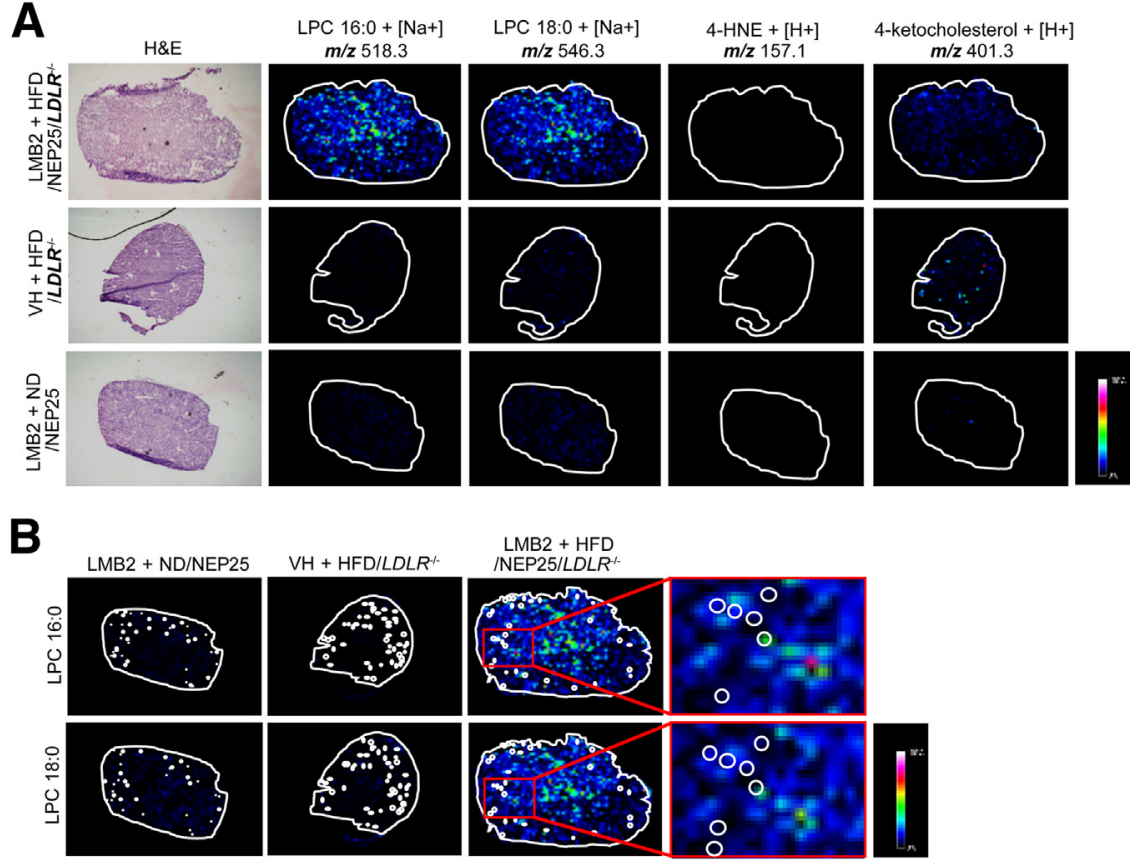

C

LPC 16:0

LPC 18:0
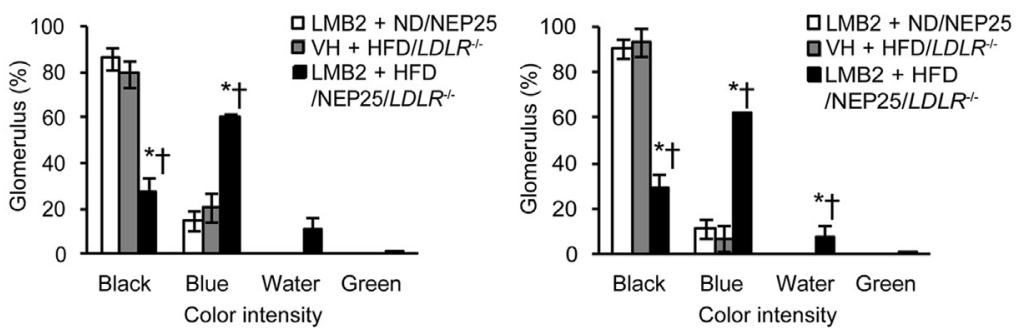

Figure 3 Matrix-assisted laser desorption/ ionization time-of-flight imaging mass spectrometry (MALDI-TOF-IMS) reveals the formation of lysophosphatidylcholine (LPC) 16:0 and 18:0 in the kidneys of the LMB2 + high-fat diet (HFD)/NEP25/low-density lipoprotein receptor deficiency $\left(L D L R^{-/-}\right)$mice. A: Heat map images of MALDI-TOF-IMS. Bright colors indicate many measured molecules (from high to low: white, red, yellow, green, water, blue, and black). Two ion signals, $m / z 518.3$ and 546.3, accumulate in notable quantities in the kidneys of the LMB2 + $\mathrm{HFD} / \mathrm{NEP} 25 / L D L R^{-/-}$mice but not in either the LMB2 + normal diet (ND)/NEP25 or the vehicle $(\mathrm{VH})+\mathrm{HFD} / L D L R^{-/-}$mice. Other oxidized LDLs, such as 7-ketocholesterol $(m / z$ 401.3) and 4hydroxy-2-nonenal $(m / z$ 157.1), were not detected in any group. Hematoxylin and eosin (H\&E) staining was performed using the same section as for MALDI-TOF-IMS. B: The location of glomeruli (white circles) using H\&E section (same section as for MALDI-TOF-IMS). The molecules representing $\mathrm{m} / z \quad 518.3$ and 546.3 (sodium-adducted LPC 16:0 and sodiumadducted LPC 18:0, respectively) are located both on glomeruli and on tubules. C: Comparison of LPC 16:0 and LPC 18:0 amounts in glomeruli using heat map images. In both LPC 16:0 and 18:0, the LMB2 + HFD/NEP25/LDLR $R^{-/}$mice display a decrease in black glomeruli and an increase in blue or water-colored glomeruli; the latter does not increase in the LMB2 + ND/NEP25 and VH + HFD/ $L D L R^{-/-}$mice. $n=3$ (A-C, LMB2 + HFD/NEP25/ $L D L R^{-/-}$mice $) ; n=4(\mathbf{A}-\mathrm{C}, \mathrm{LMB} 2+\mathrm{ND} / \mathrm{NEP} 25$ and $\mathrm{VH}+\mathrm{HFD} / L D L R^{-/-}$mice). ${ }^{*} P<0.05$ versus $\mathrm{LMB} 2+$ ND/NEP25 mice; ${ }^{\dagger} P<0.05$ versus VH $+\mathrm{HFD} / L_{L} L R^{-/-}$ mice. Original magnification, $\times 40(\mathbf{A}$ and $\mathbf{B})$. macrophage-derived foam cells were significantly elevated in the ADR $+\mathrm{HFD} / L D L R^{-1-}$ mice (Figure 1E). The formation of foam cells with oxPL was also significantly increased in the $\mathrm{ADR}+\mathrm{HFD} / L D L R^{-1-}$ mice compared with that of the other groups (Figure 1F). Glomerular oxPL deposition and macrophage infiltration showed a positive correlation (Spearman rank correlation coefficient $=0.556, P<0.0001)$. The results indicate that severe hypercholesterolemia alone is insufficient for glomerular macrophage and foam cell infiltration and that ADR-mediated chronic podocyte injury promotes macrophage-derived foam cell infiltration by ingesting oxPL.

\section{NEP25/LDLR ${ }^{-/-}$Double-Transgenic Mice Exhibit Glomerular Lipid Deposition and Podocyte Loss}

To determine whether the lipid modification (eg, accumulation and peroxidation) in the ADR $+\mathrm{HFD} / L D L R^{-/-}$ mice was caused by podocyte injury or was a direct consequence of ADR, NEP25/LDLR ${ }^{-/-}$mice were generated. The LMB2 + HFD/NEP25/LDLR ${ }^{-/-}$mice exhibited severe hypercholesterolemia, characterized by significant elevation of LDL cholesterol (Table 3). The
$\mathrm{LMB} 2+\mathrm{HFD} / \mathrm{NEP} 25 / L_{D L} R^{-/-}$mice also displayed severe proteinuria to a similar degree to that of the LMB2 + ND/NEP25 mice, in addition to significant serum creatinine elevation. Only the $\mathrm{VH}+\mathrm{HFD} / L D L R^{-/-}$mice exhibited no proteinuria and normal serum creatinine levels. In histology, the LMB2 + HFD/NEP25/LDLR ${ }^{-/-}$ mice exhibited diffuse glomerular collapse with epithelial hyperplasia to a similar degree to that of the LMB2 + ND/ NEP25 mice, whereas the $\mathrm{VH}+\mathrm{HFD} / L D L R^{-/-}$mice did not display these abnormalities (Figure 2A). Each group harbored a few macrophages and a degree of macrophagederived foam cell infiltration, although no significant difference was noted between the LMB2 + HFD/NEP25/ $L D L R^{-/-}$and $\mathrm{VH}+\mathrm{HFD} / L D L R^{-/-}$mice (Supplemental Figure S1). Notably, glomerular oil red $\mathrm{O}$-positive lipids significantly accumulated in the LMB2 + HFD/ NEP25/LDLR $R^{-/-}$mice compared with both the LMB2 + $\mathrm{ND} / \mathrm{NEP} 25$ and $\mathrm{VH}+\mathrm{HFD} / L D L R^{-1-}$ mice (Figure 2, A and B). Electron microscopy revealed that the deposited lipids were located predominantly in mesangial and glomerular endothelial cells (Figure 2D). Regression analysis clarified that the oil red $\mathrm{O}$-positive lipid deposition was inversely correlated with the number of WT-1-positive 

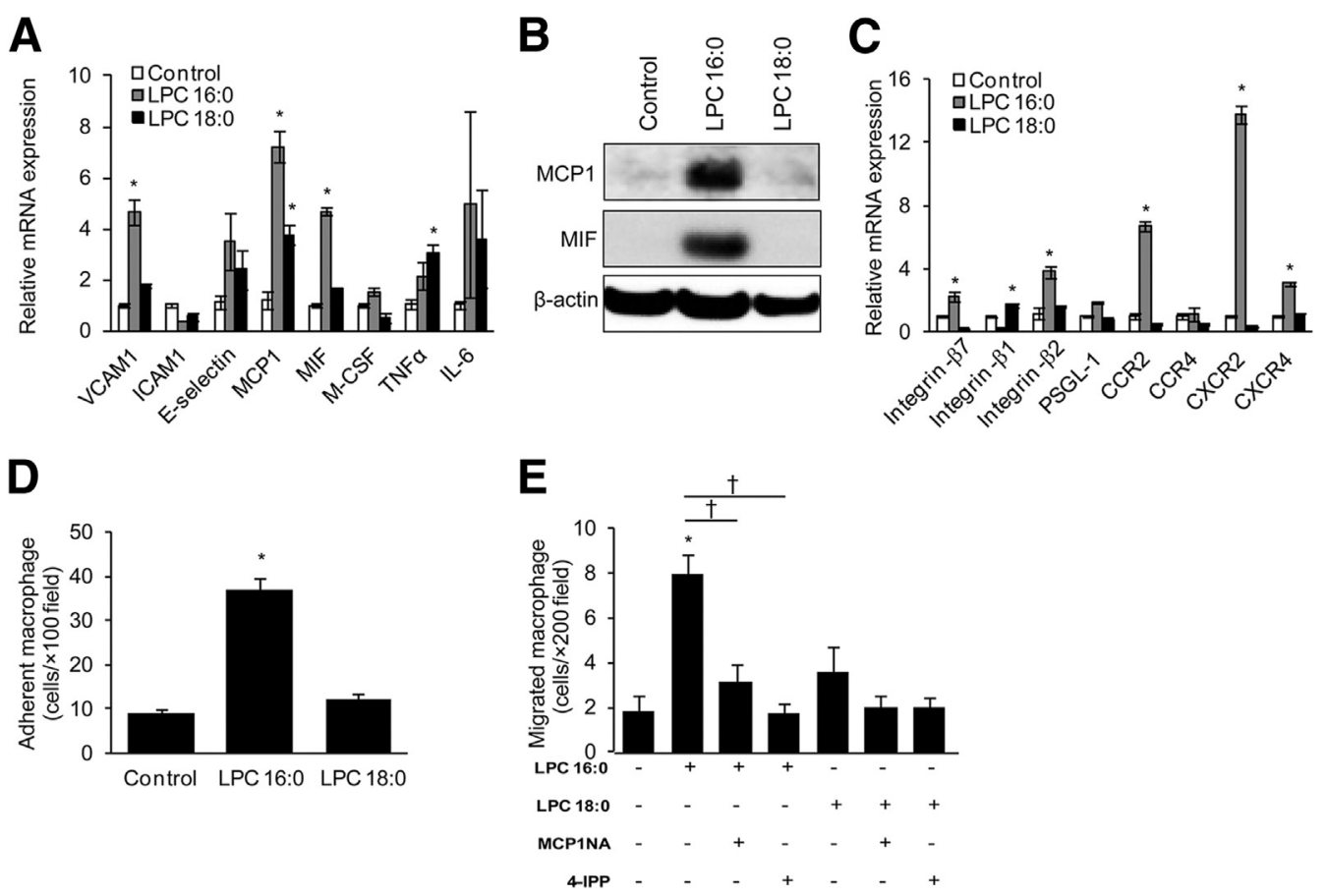

Figure 4 Lysophosphatidylcholine (LPC) 16:0-treated rat mesangial cells promote macrophage adhesion and migration by inducing the expression of adhesion molecules and chemokines in vitro. A: Quantitative RT-PCR (RT-qPCR) of LPC 16:0-treated, LPC 18:0-treated, and control-treated mesangial cells. The relative mRNA expression of vascular cell adhesion molecule-1 (VCAM-1), monocyte chemoattractant protein-1 (MCP-1), and macrophage migration inhibitory factor (MIF) increases after 8 hours' incubation of LPC 16:0. B: Western blot analysis reveals that MCP-1 and MIF protein levels increase more markedly in the LPC 16:0-treated mesangial cells compared with the control- and LPC 18:0-treated mesangial cells. In this blot, two antibodies (MCP-1 and MIF) were applied for a single membrane by stripping one and then reblotting another antibody. Thus, $\beta$-actin bands in each blot shown are the same. C: RT-qPCR reveals that C-X-C motif receptor (CXCR) 2 and CXCR4, CCR2, and integrin- $\beta 7$ mRNAs increase in the adherent macrophages of the LPC 16:0-treated mesangial cells. D: The adhesion assay reveals that the LPC 16:0-treated mesangial cells promote marked macrophage adhesion. E: The LPC 16:0-treated mesangial cells promote marked macrophage migration. The MCP-1-neutralizing antibody (MCP1NA) and the MIF inhibitor, 4-iodo-6-phenylpyrimidine (4-IPP), inhibit these processes. ${ }^{*} P<0.05$ versus the controls; ${ }^{\dagger} P<0.05$ between the two groups. ICAM, intercellular adhesion molecule; M-CSF, monocyte colonystimulating factor; TNF, tumor necrosis factor.

podocytes in the LMB2 $+\mathrm{HFD} / \mathrm{NEP} 25 / L D L R^{-1-}$ mice $\left(r=-0.8963, R^{2}=0.80, P=0.0395\right)$ (Figure 2C). The data indicate that podocyte-specific injury promotes glomerular lipid accumulation in the presence of severe hypercholesterolemia.

\section{Aberrant Formation of Lysophosphatidylcholine 16:0 and 18:0 Only in the Hypercholesterolemic NEP25/LDLR ${ }^{-/-}$Mice with Podocyte Injury}

MALDI-TOF-IMS was performed to clarify whether podocyte-specific injury promoted lipid peroxidation in the LMB2 + HFD/NEP25/LDLR ${ }^{-/-}$mice. Two signals, at $\mathrm{m} / \mathrm{z}$ 518.3 and 546.3, were significantly increased in the kidneys of the LMB2 + HFD/NEP25/LDLR ${ }^{-/-}$mice, but these were not detected in either LMB2 $+\mathrm{ND} / \mathrm{NEP} 25$ or $\mathrm{VH}+\mathrm{HFD} /$ $L D L R^{-1-}$ mice (Figure 3A). The comprehensive lipid database, LIPIDMAPS, revealed that the major candidates for these two signals are sodium-adducted LPC 16:0 and LPC 18:0, which are major components of oxLDL. ${ }^{39}$ Other ion signals of LPC 16:0 and 18:0 adducts [proton-adducted LPC 16:0 ( $\mathrm{m} / \mathrm{z}, 496.3)$, potassium-adducted LPC 16:0 ( $\mathrm{m} / \mathrm{z}$ 534.2), proton-adducted LPC 18:0 ( $\mathrm{m} / \mathrm{z} \quad 524.3)$, and potassium-adducted LPC 18:0 ( $\mathrm{m} / \mathrm{z}$ 562.2)] were all elevated in the LMB2 + HFD/NEP25/LDLR ${ }^{-1-}$ mice compared with the $\mathrm{VH}+\mathrm{HFD} / L D L R^{-/-}$and LMB2 $+\mathrm{ND} / \mathrm{NEP} 25$ mice (Supplemental Figure S2A). MS/MS analysis determined that LPC 16:0 and 18:0 were present in the kidneys of the LMB2 + HFD/NEP25/LDLR ${ }^{-/-}$mice (Supplemental Figure S2B). In addition, glomeruli containing LPC 16:0 and 18:0 significantly increased in the LMB2 + HFD/ $\mathrm{NEP} 25 / L D L R^{-/-}$mice compared with both the VH + HFD/ $L D L R^{-1-}$ and LMB2 + ND/NEP25 mice (Figure 3, B and C). OxPL, a precursor of LPC, ${ }^{39}$ was also detected in the glomeruli of the LMB2 + HFD/NEP25/LDLR ${ }^{-/-}$mice after immunostaining, supporting the MALDI-TOF-IMS LPC detection results (Supplemental Figure S3A). In contrast, other oxLDLs, including 7-ketocholesterol $(\mathrm{m} / \mathrm{z}$ 401.3) and 4-hydroxy-2-nonenal $(\mathrm{m} / \mathrm{z}, 157.1)$, were not detected (Figure 3A). In addition, malondialdehyde and $N^{\varepsilon}$-carboxymethyl-lysine, both of which are major oxLDLs, were absent in the LMB2 + HFD/NEP25/LDLR ${ }^{-/-}$mice after immunostaining (Supplemental Figure S3, B and C). The data indicate that podocyte-specific injury promotes glomerular lipid peroxidation, such as the formation of LPC 16:0 and 18:0, during severe hypercholesterolemia. 

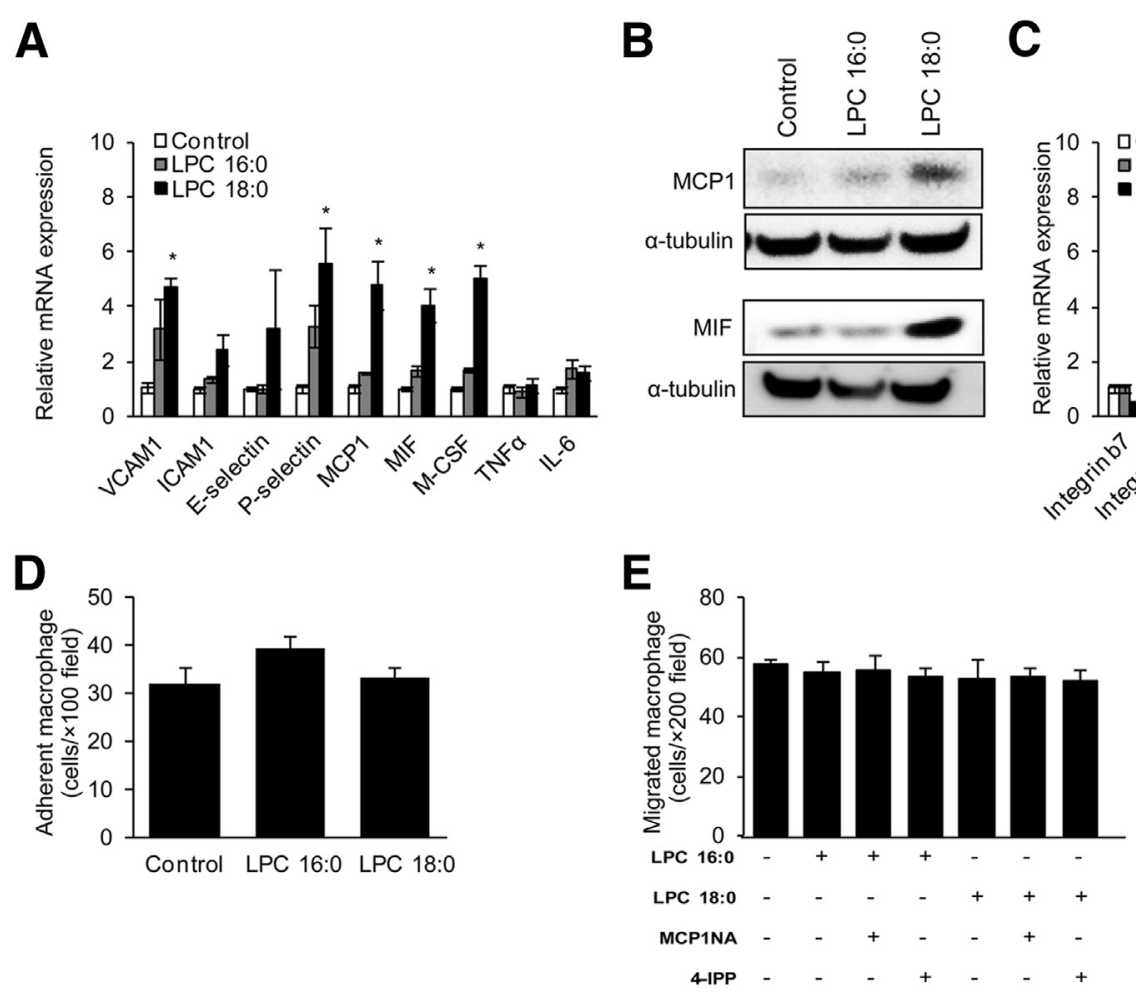

Figure 5 The lysophosphatidylcholine (LPC) 18:0-treated rat glomerular endothelial cells (GEnCs) express adhesion molecules and chemokines in vitro. A: Quantitative RT-PCR (RT-qPCR) of the LPC- or control-treated GEnCs. The relative mRNA expression of vascular cell adhesion molecule-1 (VCAM-1), Pselectin, monocyte chemoattractant protein-1 (MCP-1), macrophage migration inhibitory factor (MIF), and monocyte colony-stimulating factor (M-CSF) increases after 12 hours' incubation of LPC 18:0. B: Western blot analysis reveals that MCP-1 and MIF protein levels increase in the LPC 18:0-treated GEnCs. C: RT-qPCR reveals that most of the receptor mRNAs do not increase in adherent macrophages on either the LPC 16:0- or LPC 18:0-treated GEnCs. D: The adhesion assay reveals that the LPC 16:0 and 18:0 treatments do not promote macrophage adhesion. E: The migration assay reveals that both the LPC 16:0and LPC 18:0-treated GEnCs do not promote macrophage migration. ${ }^{*} P<0.05$ versus the controls. CXCR, C-X-C motif receptor; ICAM, intercellular adhesion molecule; 4-IPP, 4-iodo-6-phenylpyrimidine; NA, neutralizing antibody; PSGL, P-selectin glycoprotein ligand; TNF, tumor necrosis factor.

Lysophosphatidylcholine 16:0 and 18:0 Exert Different Effects on Adhesion Molecules and Chemokine Expression in Glomerular Cells in Vitro

To determine the effect of LPC on different glomerular cells, rat mesangial cells and GEnCs were stimulated by LPC 16:0 or 18:0. In the mesangial cells, the LPC 16:0 treatment promoted vascular cell adhesion molecule-1 (VCAM-1), MCP-1, and MIF mRNA expression after 8 hours of incubation, whereas LPC 18:0 promoted only mild elevation of MCP-1 and tumor necrosis factor- $\alpha$ mRNA (Figure 4A). Western blot analysis revealed an increase in MCP-1 and MIF proteins in the mesangial cells in response to the LPC 16:0 treatment (Figure 4B). In addition, LPC 16:0-treated mesangial cells promoted upregulation of receptor mRNA on rat peritoneal macrophages, including the $\mathrm{C}-\mathrm{X}-\mathrm{C}$ motif receptor (CXCR) 2 and CXCR4 (MIF receptors), ${ }^{40}$ the CCR2 (MCP-1 receptor), integrin- $\beta 7$ (VCAM-1 receptor), and integrin- $\beta 2$ (intercellular adhesion molecule-1 receptor) (Figure $4 \mathrm{C}$ ). In the adhesion and migration assay, the LPC 16:0-treated mesangial cells promoted macrophage adhesion and migration, whereas the LPC 18:0-treated mesangial cells did not (Figure 4, D and E). Neither LPC 16:0 nor 18:0 directly increased the number of migrated macrophages (control, $4.2 \pm 1.1$ cells/field; LPC 16:0, $3.8 \pm 0.8$ cells/ field; LPC 18:0, $2.3 \pm 0.7$ cells/field; data not significant). MCP-1 neutralizing antibody and the MIF inhibitor, 4-iodo-6-phenylpyrimidine, inhibited macrophage migration in the LPC 16:0-treated mesangial cells (Figure 4E).

Regarding GEnCs, the LPC 18:0 treatment promoted VCAM-1, P-selectin, MCP-1, MIF, and monocyte colonystimulating factor mRNA up-regulation after 12 hours of incubation, whereas the LPC 16:0 treatment did not (Figure 5A). Western blot analysis revealed that the MCP-1 and MIF proteins increased only in the LPC 18:0-treated GEnCs (Figure 5B). In contrast, in the GEnCs, the LPC 16:0 and 18:0 treatments did not promote the up-regulation of receptor mRNAs on rat peritoneal macrophages, except for CCR2 in the LPC 16:0-treated GEnCs (Figure 5C). In both the adhesion and migration assays, the LPC 16:0- and 18:0-treated GEnCs did not promote macrophage adherence or migration (Figure 5, D and E). These results suggest that the contribution of each LPC to the expression of adhesion molecules and chemokines differed in the mesangial cells and GEnCs. 


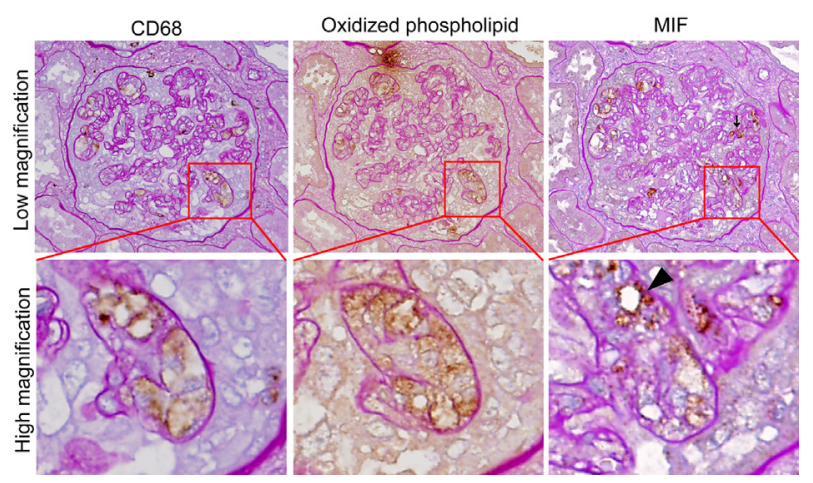

Figure 6 Colocalization of oxidized phospholipid (oxPL) and macrophage migration inhibitory factor (MIF) with CD68-positive macrophages in human focal segmental glomerulosclerosis (FSGS). CD68-positive macrophages infiltrate the intracapillary region at the site of epithelial hyperplasia. 0xPL localizes in macrophage-derived foam cells. MIF is also expressed by macrophages in the mesangial area (arrow) and intracapillary spaces (arrowhead). Periodic acid-Schiff staining is displayed as a counterstain. Original magnifications: $\times 200$ (top panels); $\times 800$ (bottom panels).

\section{Colocalization of Macrophage MIF and oxPL-Containing Foam Cells in Human FSGS}

In cellular variant of human FSGS, serial sections showed oxPL in the CD68-positive macrophages, which infiltrated the tuft (Figure 6). In addition, MIF was expressed in the tuft and background mesangial area, corresponding to the macrophage-derived foam cell infiltration. These staining patterns were not observed in the unaffected glomeruli in the same samples.

\section{Scavenger Receptors and the Expression of Cholesterol Efflux Transporters in Vitro and in Human FSGS}

Effects of LPC 16:0 and LPC 18:0 on changes of scavenger receptors and cholesterol efflux transporters in macrophages were assessed by RT-qPCR using LPC-treated rat peritoneal macrophages (Supplemental Figure S4A). LPC 16:0 treatment down-regulated mRNAs of panels of scavenger receptors, such as LOX-1, scavenger receptor class A (SR-A) type 1, SR-A type 2, and CD36, and cholesterol efflux transporters, such as ATP-binding cassette subfamily A1 and ATP-binding cassette subfamily G1. LPC 18:0 treatment decreased SR-A type 1 and SR-A type 2 mRNA expression.

In human FSGS, CD68-positive macrophages also expressed scavenger receptors, LOX-1 and SR-BI, although the expression was relatively weak (Supplemental Figure S4B). These results suggest that LPC 16:0, rather than LPC 18:0, associates with lipid ingestion of macrophages to transform into foam cells through down-regulation of cholesterol efflux transporters.

\section{Discussion}

The present study is the first to show the possible mechanism underlying glomerular foam cell formation in FSGS, in which podocyte injury plays a novel role (Figure 7).
First, both LMB2-treated NEP25 mice and the HFD/ $L D L R^{-1-}$ mice failed to show glomerular influx of macrophages, indicating that acute and fulminant podocyte injury or long-term severe hypercholesterolemia alone did not induce glomerular macrophages. By contrast, the ADR-treated hypercholesterolemic $L D L R^{-/-}$mice developed FSGS lesions, accompanied by macrophage influx; ADR had no effect on the glomerular macrophages in the $\mathrm{ND} / L D L R^{-/-}$mice. More important, the ADR-treated hypercholesterolemic $L D L R^{-/-}$ mice showed a significant amount of lipid deposition in the glomeruli and lipid peroxidation, as well as oxLDL ingestion, at 6 weeks, suggesting that the chronic podocyte injury and marked hypercholesterolemia synergistically accelerated glomerular foam cell formation. These findings confirm previous observations of increased glomerular macrophages in puromycin aminonucleoside nephrosis in hypercholesterolemia and increased deposition of oxLDL in the glomeruli. ${ }^{22,23,41,42}$ Peroxidized lipid induces the migration of macrophages and both ADR and puromycin aminonucleoside nephrosis directly modify lipid peroxidation

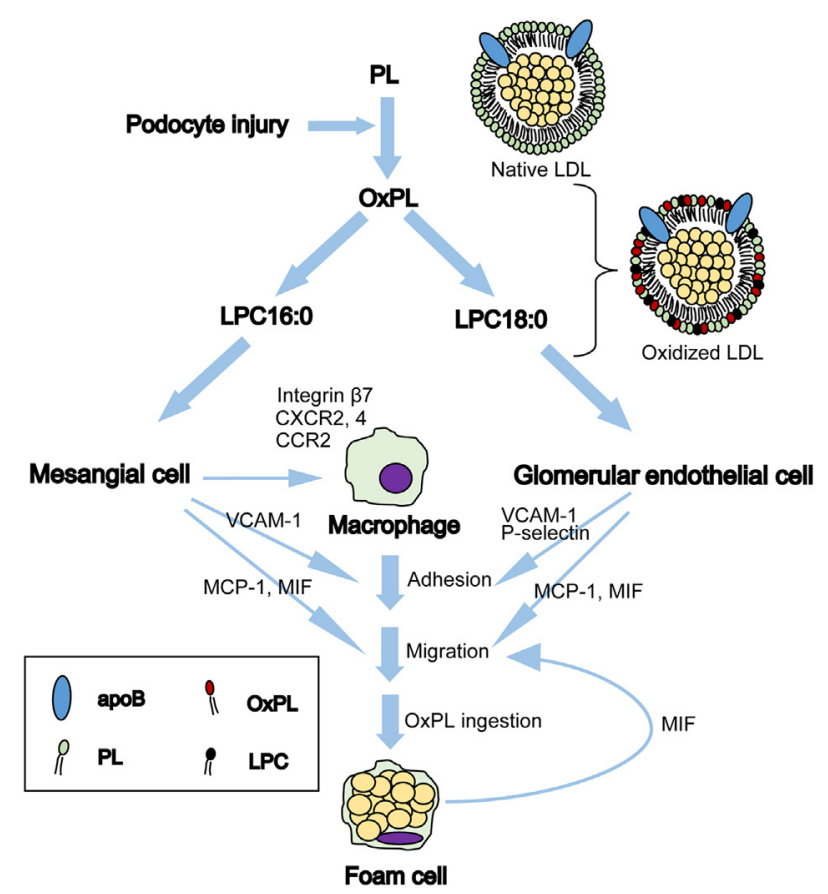

Figure 7 Schematic model of the underlying molecular network promoting glomerular foam cells in focal segmental glomerulosclerosis (FSGS). Podocyte injury elicits glomerular lipid deposition and phospholipid peroxidation in the presence of hypercholesterolemia. The metabolite of the oxidized phospholipid, oxPL [ie, lysophosphatidylcholine (LPC) 16:0 and 18:0], exerts different effects on the mesangial and glomerular endothelial cells. LPC 16:0-stimulated mesangial cells express adhesion molecules and chemokines and induce the expression of these receptors on macrophages. LPC 18:0 affects only the glomerular endothelial cells. These molecular environments promote macrophage adhesion and migration. Finally, the macrophages ingest oxidized LDL, thereby transforming into foam cells, and also express migration inhibitory factor (MIF), which may facilitate further macrophage recruitment into the glomerulus. apoB, apolipoprotein $\mathrm{B}$; CXCR, C-X-C motif receptor; LDL, low-density lipoprotein; MCP, monocyte chemoattractant protein; VCAM, vascular cell adhesion molecule. 
by the induction of reactive oxygen species. ${ }^{43}$ In addition, ADR might influence not only podocytes but also glomerular endothelial cells and monocyte activation. ${ }^{44}$ In this regard, we showed that the HFD/NEP25/LDLR ${ }^{-/-}$ mice with podocyte-selective injury showed a significant amount of glomerular lipid deposition, which inversely correlated with the podocyte number. In addition, a lipidomics study showed lipid peroxidation in the kidney, including glomeruli, as revealed by lipidomics profiles and histology in the same section of NEP25/LDLR $R^{-1-}$ mice. These results suggest that podocyte loss correlates with glomerular lipid deposition and peroxidation on the basis of hypercholesterolemia.

OxLDL has a variety of components that are not present in nature. ${ }^{45}$ Native LDL reacts with oxidative reagents and is converted to oxPL, which is transformed to LPC by hydrolysis. ${ }^{39}$ LPC has various physiological functions, such as macrophage recruitment through activation of adhesion molecules, inflammatory cytokines, and chemokines in various cell types, as shown in atherosclerosis. ${ }^{39}$ LPC is composed of a variety of molecular species, depending on the carboxyl chain number, and these may have different physiological functions. ${ }^{46,47}$ In this study, MALDI-TOFIMS, a lipidomics approach, ${ }^{48}$ detected two peaks of peroxidized lipids, LPC 16:0 and 18:0, de novo in the glomeruli of LMB2-treated HFD/NEP25/LDLR ${ }^{-1-}$ mice. These peaks were absent in both the LMB2-treated NEP25 mice and the $\mathrm{HFD} / L D L R^{-1-}$ mice, indicating that podocyte injury drives the formation of specific oxidized lipid species in the presence of hypercholesterolemia.

Glomerular foam cell formation in FSGS may develop by a stepwise process, as shown in atherosclerosis. Entrapment of circulating monocytes within the glomerular tuft requires an array of changes in the expression of cytokines and adhesion molecules in glomerular cells, as well as their receptors in monocytes, as part of a complex in situ network. LPC 16:0 and 18:0, detected by lipidomics during podocyte injury, may change the expression of chemokines and adhesion molecules in glomerular cells. Both LPCs act on macrophages through stimulation of glomerular cells; neither exerted direct action on macrophages. The mesangial cells incubated with LPC 16:0 induced VCAM-1, MCP-1, and MIF, with simultaneous expression of their receptors, integrin- $\beta 7$, CCR2, CXCR2, and CXCR4, in co-cultured macrophages. In contrast, LPC 18:0 promoted the expression of VCAM-1 and P-selectin, as well as MCP-1 and MIF, in glomerular endothelial cells, whereas LPC 18:0-stimulated glomerular endothelial cells had no effect on the expression of macrophage receptors. In addition, monocyte colony-stimulating factor, which is known to induce the transformation of monocytes to macrophages, ${ }^{13,49}$ was upregulated only in the LPC 18:0-treated glomerular endothelial cells. On the basis of these observations, we are the first to demonstrate that podocyte injury-driven lipid peroxidation produces two major LPCs in situ, which exert different effects on the expression of chemokines and adhesion molecules in mesangial and glomerular endothelial cells. Because LPC
16:0- primed mesangial cells induced cytokine and chemokine receptors in macrophages simultaneously, LPC-induced aberrant intracapillary signaling of glomerular cells may allow circulating monocytes to adhere to endothelial cells and migrate into the mesangium by transforming into macrophages.

Activated macrophages transform into foam cells by ingesting oxLDL through specific scavenger receptors expressed in nature. ${ }^{50}$ Because oxLDL has been shown to promote further expression of scavenger receptors, such as CD68, ${ }^{50}$ glomerular lipid peroxidation may accelerate foam cell transformation, as seen in atherosclerosis. We showed the localization of oxLDL in CD68-positive macrophages in the ADR-treated $\mathrm{HFD} / L D L R^{-1-}$ mice, as well as in the human cellular variant of FSGS. In addition, LPC 16:0 treatment down-regulated various scavenger receptor and cholesterol efflux transporter expression on macrophages in vitro, suggesting that LPC 16:0 promotes lipid accumulation on macrophages through down-regulation of cholesterol efflux transporters. Although our results are somewhat different from previous reports showing promotion of scavenger receptor by oxLDL, ${ }^{50}$ this inconsistency might be because of the difference between oxLDL and its specific components used.

Glomerular lipid peroxidation in FSGS is likely to be promoted in situ, associated with overlaying podocyte injury, but this is still unproved. Because previous studies showed that the levels of serum and local oxLDL were elevated in FSGS patients compared with minimal change disease patients, already formed peroxidized lipids in the circulation may possibly be involved. ${ }^{51,52}$ In human FSGS, we show the prominent deposition of oxLDL in the sclerotic segment but not in the unaffected glomerular tuft. In addition, oxLDL was found in the foam cells together with MIF, suggesting that podocyte injury promotes lipid peroxidation locally. Clearly, more experiments are needed to link podocyte injury and lipid peroxidation. Nevertheless, it is known that reactive oxygen species are the major factors in lipid peroxidation and that podocytes synthesize them in response to various stressors. ${ }^{53-56}$ Future studies need to clarify what kind of podocyte injury (ie, severity, duration, or type) promotes glomerular lipid peroxidation, because podocyte injury also causes minimal change disease, without any significant elevation in local lipid peroxidation.

Various FSGS models with hypercholesterolemia have suggested that glomerular foam cells promote development of FSGS, yet actual relations between them still remain to be elucidated. In our data, a similar incidence of FSGS lesions in ADR-treated $L D L R^{-1-}$ mice, with or without hypercholesterolemia, despite significantly higher oil red $\mathrm{O}$ and oxLDL deposition, and increase of oxPL-containing foam cells in ADR-treated HFD/LDLR ${ }^{-1-}$ mice, suggests that macrophage infiltration and foam cell formation are a surrogate phenomenon during podocyte injury-caused FSGS.

In conclusion, podocyte injury-driven lipid modification represents a novel mechanism underlying FSGS. Chronic podocyte injury promoted hypercholesterolemia-based lipid deposition and the deposition of specific components of 
oxLDL formation (ie, LPC 16:0 and 18:0) in the glomerulus. These aberrant LPCs may synergistically lead to the formation of glomerular macrophage-derived foam cells by stimulating the expression of adhesion molecules and chemokines in mesangial and glomerular endothelial cells.

\section{Acknowledgments}

We thank Drs. Michito Hamada and Satoru Takahashi (University of Tsukuba, Tsukuba, Japan) for $L D L R^{-1-}$ mice, Dr. Shuji Kondo (Tokushima University, Tokushima, Japan) for the rat mesangial cell line, Dr. Masaomi Nangaku (University of Tokyo, Tokyo, Japan) for the rat glomerular endothelial cell line, and Kouichiro Kako and Junichi Ishida (University of Tsukuba) for their advice pertaining to the MALDI-TOF-IMS experiments.

\section{Supplemental Data}

Supplemental material for this article can be found at http://dx.doi.org/10.1016/j.ajpath.2015.04.007.

\section{References}

1. D’Agati VD, Kaskel FJ, Falk RJ: Focal segmental glomerulosclerosis. N Engl J Med 2011, 365:2398-2411

2. Wharram BL, Goyal M, Wiggins JE, Sanden SK, Hussain S, Filipiak WE, Saunders TL, Dysko RC, Kohno K, Holzman LB, Wiggins RC: Podocyte depletion causes glomerulosclerosis: diphtheria toxin-induced podocyte depletion in rats expressing human diphtheria toxin receptor transgene. J Am Soc Nephrol 2005, 16:2941-2952

3. Matsusaka T, Xin J, Niwa S, Niwa S, Kobayashi K, Akatsuka A, Hashizume H, Wang QC, Pastan I, Fogo AB, Ichikawa I: Genetic engineering of glomerular sclerosis in the mouse via control of onset and severity of podocyte-specific injury. J Am Soc Nephrol 2005, 16: 1013-1023

4. Asano T, Niimura F, Pastan I, Fogo AB, Ichikawa I, Matsusaka T: Permanent genetic tagging of podocytes: fate of injured podocytes in a mouse model of glomerular sclerosis. J Am Soc Nephrol 2005, 16:2257-2262

5. D'Agati VD: Pathologic classification of focal segmental glomerulosclerosis. Semin Nephrol 2003, 23:117-134

6. D'Agati VD, Fogo AB, Bruijn JA: Pathologic classification of focal segmental glomerulosclerosis: a working proposal. Am J Kidney Dis 2004, 43:368-382

7. Stokes MB, Markowitz GS, D'Agati VD: Cellular focal segmental glomerulosclerosis: clinical and pathologic features. Kidney Int 2006, 70:1783-1792

8. Takahashi S, Hiromura K, Tsukida M, Ohishi Y, Hamatani H, Sakurai N, Sakairi T, Ikeuchi H, Kaneko Y, Maeshima A, Kuroiwa T, Yokoo H, Aoki T, Nagata M, Nojima Y: Nephrotic syndrome caused by immune-mediated acquired LCAT deficiency. J Am Soc Nephrol 2013, 24:1305-1312

9. Buja LM, Kovanen PT, Bilheimer DW: Cellular pathology of homozygous familial hypercholesterolemia. Am J Pathol 1979, 97: 327-357

10. Kasiske BL, O'Donnell MP, Schmitz PG, Kim Y, Keane WF: Renal injury of diet-induced hypercholesterolemia in rats. Kidney Int 1990, 37:880-891

11. Kasiske BL, O'Donnell MP, Cleary MP, Keane WF: Treatment of hyperlipidemia reduces glomerular injury in obese Zuker rats. Kidney Int 1988, 33:667-672
12. Hattori M, Nikolic-Paterson DJ, Miyazaki K, Isbel NM, Atkins RC, Kawaguchi H, Ito K: Mechanisms of glomerular macrophage infiltration in lipid-induced renal injury. Kidney Int Suppl 1999, 71: S47-S50

13. Miyazaki K, Isbel NM, Lan HY, Hattori M, Ito K, Bacher M, Bucala R, Atkins RC, Nikolic-Paterson DJ: Up-regulation of macrophage colony-stimulating factor (M-CSF) and migration inhibitory factor (MIF) expression and monocyte recruitment during lipid-induced glomerular injury in the exogenous hypercholesterolaemic (ExHC) rat. Clin Exp Immunol 1997, 108:318-323

14. Bruneval P, Bariéty J, Bélair MF, Mandet C, Heudes D, Nicoletti A: Mesangial expansion associated with glomerular endothelial cell activation and macrophage recruitment is developing in hyperlipidaemic apoE null mice. Nephrol Dial Transplant 2002, 17:2099-2107

15. Wen M, Segerer S, Dantas M, Brown PA, Hudkins KL, Goodpaster T, Kirk E, LeBoeuf RC, Alpers CE: Renal injury in apolipoprotein E-deficient mice. Lab Invest 2002, 82:999-1006

16. Furuta T, Saito T, Otaka T, Soma J, Obara K, Abe K, Yoshinaga K: The role of macrophages in diabetic glomerulosclerosis. Am J Kidney Dis 1993, 21:480-485

17. Howie AJ: Changes at the glomerular tip: a feature of membranous nephropathy and other disorders associated with proteinuria. J Pathol 1986, 150:13-20

18. Roberts IS: Pathology of IgA nephropathy. Nat Rev Nephrol 2014, $10: 445-454$

19. Howie AJ: Pathology of minimal change nephropathy and segmental sclerosing glomerular disorders. Nephrol Dial Transplant 2003, Suppl 6:vi33-vi38

20. Hattori M, Horita S, Yoshioka T, Yamaguchi Y, Kawaguchi Y, Ito K Mesangial phenotypic changes associated with cellular lesions in primary focal segmental glomerulosclerosis. Am J Kidney Dis 1997, 30:632-638

21. Saito T, Ootaka T, Sato H, Furuta T, Sato T, Soma J, Abe K, Yoshinaga K: Participation of macrophages in segmental endocapillary proliferation preceding focal glomerular sclerosis. J Pathol 1993, 170:179-185

22. Diamond JR, Karnovsky MJ: Focal and segmental glomerulosclerosis: analogies to atherosclerosis. Kidney Int 1988, 33:917-924

23. Magil AB, Frohlich JJ, Innis SM, Steinbrecher UP: Oxidized lowdensity lipoprotein in experimental focal glomerulosclerosis. Kidney Int 1993, 43:1243-1250

24. Lee HS, Jeong JY, Kim BC, Kim YS, Zhang YZ, Chung HK: Dietary antioxidant inhibits lipoprotein oxidation and renal injury in experimental focal segmental glomerulosclerosis. Kidney Int 1997, 51: $1151-1159$

25. Ueno T, Kobayashi N, Nakayama M, Takashima Y, Ohse T, Pastan I, Pippin JW, Shankland SJ, Uesugi N, Matsusaka T, Nagata M: Aberrant Notch1-dependent effects on glomerular parietal epithelial cells promotes collapsing focal segmental glomerulosclerosis with progressive podocyte loss. Kidney Int 2013, 83:1065-1075

26. Osuga J, Yonemoto M, Yamada N, Shimano H, Yagyu H, Ohashi K, Harada K, Kamei T, Yazaki Y, Ishibashi S: Cholesterol lowering in low density lipoprotein receptor knockout mice overexpressing apolipoprotein E. J Clin Invest 1998, 102:386-394

27. Papeta N, Zheng Z, Schon EA, Brosel S, Altintas MM, Nasr SH Reiser J, D'Agati VD, Gharavi AG: Prkdc participates in mitochondrial genome maintenance and prevents Adriamycin-induced nephropathy in mice. J Clin Invest 2010, 120:4055-4064

28. Friedewald WT, Levy RI, Fredrickson DS: Estimation of the concentration of low-density lipoprotein cholesterol in plasma, without use of the preparative ultracentrifuge. Clin Chem 1972, 18:499-502

29. Lalowski M, Magni F, Mainini V, Monogioudi E, Gotsopoulos A, Soliymani R, Chinello C, Baumann M: Imaging mass spectrometry: a new tool for kidney disease investigations. Nephrol Dial Transplant 2013, 28:1648-1656

30. Koizumi S, Yamamoto S, Hayasaka T, Konishi M, YamaguchiOkada M, Gotou-Inoue N, Sugihara Y, Setou M, Namba H: Imaging 
mass spectrometry revealed the production of lyso-phosphatidylcholine in the injured ischemic rat brain. Neuroscience 2010, 168:219-225

31. Tanaka T, Miyata T, Inagi R, Kurokawa K, Adler S, Fujita T, Nangaku M: Hypoxia-induced apoptosis in cultured glomerular endothelial cells: involvement of mitochondrial pathways. Kidney Int 2003, 64:2020-2032

32. Kagami S, Kondo S, Urushihara M, Löster K, Reutter W, Saijo T, Kitamura A, Kobayashi S, Kuroda Y: Overexpression of alphalbeta1 integrin directly affects rat mesangial cell behavior. Kidney Int 2000, 58:1088-1097

33. Rong JX, Berman JW, Taubman MB, Fisher EA: Lysophosphatidylcholine stimulates monocyte chemoattractant protein-1 gene expression in rat aortic smooth muscle cells. Arterioscler Thromb Vasc Biol 2002, 22:1617-1623

34. Takeshita S, Inoue N, Gao D, Rikitake Y, Kawashima S, Tawa R, Sakurai H, Yokoyama M: Lysophosphatidylcholine enhances superoxide anions production via endothelial NADH/NADPH oxidase. J Atheroscler Thromb 2000, 7:238-246

35. Kugiyama K, Sugiyama S, Ogata N, Oka H, Doi H, Ota Y, Yasue H: Burst production of superoxide anion in human endothelial cells by lysophosphatidylcholine. Atherosclerosis 1999, 143: 201-204

36. Zhou X, Li J, Yang W: Calcium/calmodulin-dependent protein kinase II regulates cyclooxygenase-2 expression and prostaglandin E2 production by activating cAMP-response element-binding protein in rat peritoneal macrophages. Immunology 2014, 143: 287-299

37. Luo Y, Laning J, Hayashi M, Hancock PR, Rollins B, Dorf ME: Serologic analysis of the mouse beta chemokine JE/monocyte chemoattractant protein-1. J Immunol 1994, 153:3708-3716

38. Winner M, Meier J, Zierow S, Rendon BE, Circhlow GV, Riggs R, Bucala R, Leng L, Smith N, Lolis E, Trent JO, Mitchell RA: A novel, macrophage migration inhibitory factor suicide substrate inhibits motility and growth of lung cancer cells. Cancer Res 2008, 68: $7253-7257$

39. Matsumoto T, Kobayashi T, Kamata K: Role of lysophosphatidylcholine (LPC) in atherosclerosis. Curr Med Chem 2007, 14:3209-3220

40. Bernhagen J, Krohn R, Lue H, Gregory JL, Zernecke A, Koenen RR, Dewor M, Georgiev I, Schober A, Leng L, Kooistra T, FingerleRowson G, Ghezzi P, Kleemann R, McColl SR, Bucala R, Hickey MJ, Weber C: MIF is a noncognate ligand of CXC chemokine receptors in inflammatory and atherogenic cell recruitment. Nat Med 2007, 13:587-596

41. Cheng ZZ, Pätäri A, Aalto-Setälä K, Novikov D, Schlöndorff D, Holthöfer H: Hypercholesterolemia is a prerequisite for puromycin inducible damage in mouse kidney. Kidney Int 2003, 63:107-112

42. Diamond JR, Karnovsky MJ: Exacerbation of chronic aminonucleoside nephrosis by dietary cholesterol supplementation. Kidney Int 1987, 32:671-677
43. Zhu C, Xuan X, Che R, Ding G, Zhao M, Bai M, Jia Z, Huang S, Zhang A: Dysfunction of the PGC- $1 \alpha$-mitochondria axis confers adriamycin-induced podocyte injury. Am J Physiol Renal Physiol 2014, 306:F1410-F1417

44. Jeansson M, Bjorck K, Tenstad O, Haraldsson B: Adriamycin alters glomerular endothelium to induce proteinuria. J Am Soc Nephrol 2009, 20:114-122

45. Parthasarathy S, Santanam N, Ramachandran S, Meilhac O: Oxidants and antioxidants in atherogenesis: an appraisal. J Lipid Res 1999, 40: $2143-2157$

46. Aiyar N, Disa J, Ao Z, Ju H, Nerurkar S, Willette RN, Macphee CH, Johns DG, Douglas SA: Lysophosphatidylcholine induces inflammatory activation of human coronary artery smooth muscle cells. Mol Cell Biochem 2007, 295:113-120

47. Liu-Wu Y, Hurt-Camejo E, Wiklund O: Lysophosphatidylcholine induces the production of IL-1beta by human monocytes. Atherosclerosis 1998, 137:351-357

48. Schiller J, Süss R, Arnhold J, Fuchs B, Lessig J, Müller M, Petković M, Spalteholz H, Zschörnig O, Arnold K: Matrix-assisted laser desorption and ionization time-of-flight (MALDI-TOF) mass spectrometry in lipid and phospholipid research. Prog Lipid Res 2004, 43:449-488

49. Takahashi K, Takeya M, Sakashita N: Multifunctional roles of macrophages in the development and progression of atherosclerosis in humans and experimental animals. Mec Electron Microsc 2002, 35 : $179-203$

50. Villiers WJS, Smart EJ: Macrophage scavenger receptors and foam cell formation. J Leukoc Biol 1999, 66:740-746

51. Lee HS, Kim YS: Identification of oxidized low density lipoprotein in human renal biopsies. Kidney Int 1998, 54:848-856

52. Nezhad ST, Momeni B, Basiratnia M: Glomerular malondialdehyde levels in patients with focal and segmental glomerulosclerosis and minimal change disease. Saudi J Kidney Dis Transpl 2010, 21: 886-891

53. Greiber S, Münzel $\mathrm{T}$, Kästner $\mathrm{S}$, Müller $\mathrm{B}$, Schollmeyer $\mathrm{P}$, Pavenstädt $\mathrm{H}$ : NAD(P)H oxidase activity in cultured human podocytes: effects of adenosine triphosphate. Kidney Int 1998, 53: 654-663

54. Wang Z, Wei X, Zhang Y, Ma X, Li B, Zhang S, Du P, Zhang X, Yi F: NADPH-oxidase-derived ROS contributes to upregulation of TRPC6 expression in puromycin aminonucleoside-induced podocyte injury. Cell Physiol Biochem 2009, 24:619-626

55. Chen S, Meng XF, Zhang C: Role of NADPH oxidase-mediated reactive oxygen species in podocyte injury. Biomed Res Int 2013, 2013:839761

56. Nosadini R, Tonolo G: Role of oxidized low density lipoproteins and free fatty acids in the pathogenesis of glomerulopathy and tubulointerstitial lesions in type 2 diabetes. Nutr Metab Cardiovasc Dis 2011, 21:79-85 